\title{
Challenges and discoveries in the total synthesis of complex
}

\section{5 polyketide natural products}

\author{
Ian Paterson ${ }^{*}$ and Nelson Y. S. Lam
}

University Chemical Laboratory, Lensfield Road, Cambridge, CB2 1EW, U.K.

*Corresponding author. Email: ip100@cam.ac.uk

\begin{abstract}
Structurally complex polyketide natural products, isolated from a variety of marine and terrestrial sources, continue to provide a valuable source of rewarding targets for the synthetic

15 chemist to tackle. In this account, we provide an overview of the total synthesis of several structurally fascinating polyketides with promising anticancer activity completed in our group based on our versatile asymmetric aldol methodology - spirastrellolide A methyl ester, leiodermatolide, rhizopodin and chivosazole $\mathrm{F}$ - and highlight the unanticipated challenges and discoveries encountered.
\end{abstract}

\section{Introduction}

Through aeons of evolution, nature has gifted us with a seemingly limitless source of important secondary metabolites. Such compounds are often astoundingly intricate in terms of their molecular architecture, with stereochemically elaborate scaffolds that dwarf structures 
25 conceived by mankind. Unsurprisingly, such extraordinary structures demand effective methodologies and strategies, along with hard work and perseverance, to ensure a successful outcome from a suitably focused synthetic campaign. Furthermore, the vanishingly low isolation yields of such natural products can preclude their full stereochemical assignment, rendering total synthesis a valuable tool for structural elucidation. ${ }^{1-5}$

Amongst the vast chemical space carved out by nature are the polyketides, typified by their dazzling array of functionality and stereochemistry, providing a testing intellectual challenge for the synthetic chemist. Enticed by these intriguing structures, which generally have impressive biological activities, ${ }^{6}$ our group has had a longstanding interest in the development of novel synthetic methods and strategies that are both robust and, where required, flexible. In

35 this context, the efficiency of our suite of versatile boron-mediated aldol reactions has proved invaluable for the controlled installation of the highly oxygenated frameworks of these captivating natural products. ${ }^{7-9}$

In this account, we provide an overview of recent research endeavors that have culminated in the total synthesis of several challenging polyketide natural products with promising 40 anticancer activity in our group: spirastrellolide A methyl ester (1), leiodermatolide (2), rhizopodin (3), and chivosazole F (4) (Figure 1). In particular, we highlight the unexpected obstacles encountered and subsequent discoveries that resulted in the successful total syntheses of these highly challenging targets. 


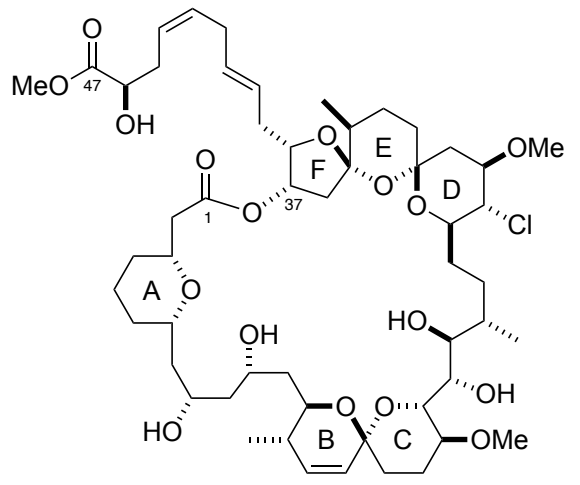

Spirastrellolide A methyl ester (1)

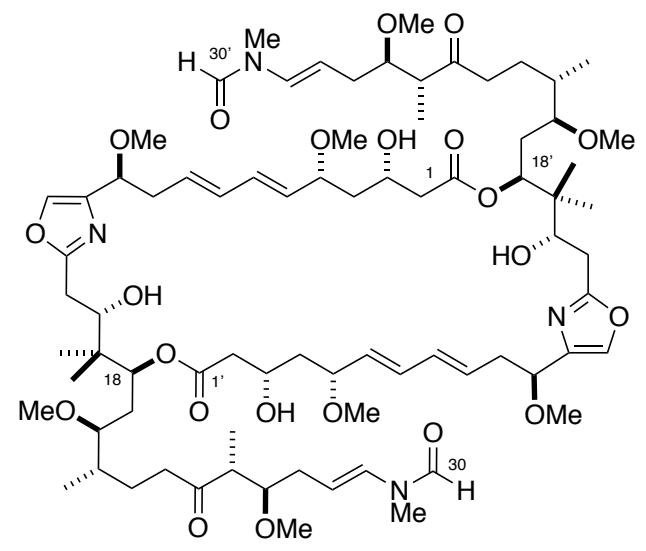

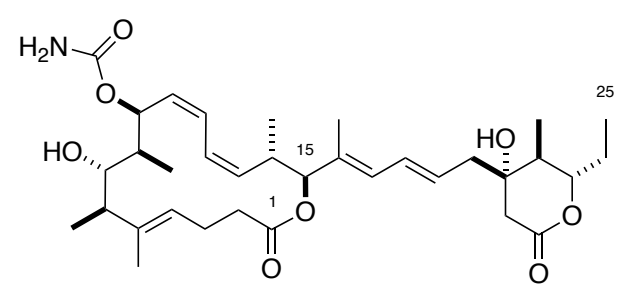

Leiodermatolide (2)

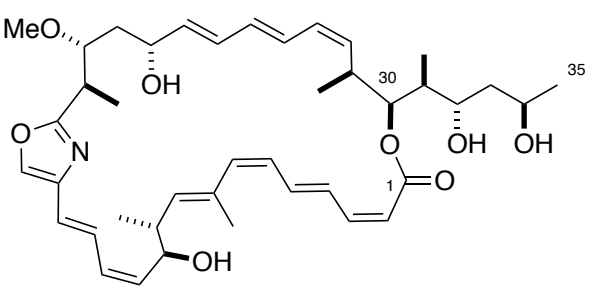

Chivosazole F (4)

Rhizopodin (3)

Figure 1. Structures of spirastrellolide A methyl ester (1), leiodermatolide (2), rhizopodin (3) and chivosazole F (4)

\section{Spirastrellolide A methyl ester}

The spirastrellolides constitute an extraordinary family of spiroacetal macrolides first isolated by Andersen and co-workers in 2003 from extracts of the Caribbean sponge Spirastrella coccinea. ${ }^{10}$ The most abundant congener, spirastrellolide A (1) (isolated as the corresponding methyl ester) exhibits striking structural complexity, containing 20 stereocentres, a 38-membered macrolactone and a nine-carbon side chain featuring a $(Z, E)$ -

55 1,4-diene. ${ }^{11-15}$ The macrocycle itself contains a tetrahydropyran (A ring), a bicyclic 6,6spiroacetal (BC rings) and a tricyclic 5,6,6-spiroacetal (DEF rings) featuring a chlorine atom 
at C28. Additionally, spirastrellolide A was found to exhibit potent antimitotic properties via selective protein phosphatase $2 \mathrm{~A}$ inhibition $\left(\mathrm{IC}_{50}=1 \mathrm{nM}\right) \cdot{ }^{10,12}$ Beyond the obvious potential as a novel anticancer lead, such phosphatase inhibitors have also shown therapeutic promise 60 in tackling obesity, autoimmune conditions and neurodegenerative disorders. ${ }^{16}$ The combination of the synthetic challenge posed by their architectural complexity and promising biological activity has rendered the spirastrellolides the focus of intense research efforts from numerous groups. ${ }^{15}$ Despite this, only five completed syntheses have been reported to date, ${ }^{17-}$ ${ }^{20}$ two of which are from our group. ${ }^{21-24}$

Our efforts towards spirastrellolide A methyl ester began soon after disclosure of the originally proposed structure and our synthetic approach evolved concurrently with structural determination studies on this moving target. ${ }^{25} \mathrm{~A}$ flexible endgame was a strict requirement as a consequence of the ambiguity surrounding the C46 hydroxyl stereocentre. Specifically, our initial strategy in face of these imposed requirements involved a modular approach to macrocycle formation, resulting in the successful assembly of the complete ABCDEF ring system, followed by late-stage side chain attachment to facilitate preparation of both possible C46 diastereomers. ${ }^{26}$

With advanced intermediate 5 (Scheme 1) in hand after a sustained campaign of dedicated efforts, ${ }^{22,26}$ synthesis completion appeared tantalisingly close. Unfortunately, 75 selective removal of the C40 silyl protecting group to enable side chain incorporation proved to be a major obstacle. In the end, a global deprotection, followed by protecting group adjustment, was required. Oxidation to the corresponding aldehyde 6 then proceeded smoothly and set the scene for homologation. At this point, a variety of organometallic addition reactions were trialled unsuccessfully. We surmised that these failures were likely to be a 80 reflection of the steric constraints imposed on the $\mathrm{C} 40$ aldehyde by the proximal cage-like macrocycle. After exhaustive experimentation, it was found that a simple Wittig olefination 
reaction could be used to access a terminal alkene, thereby allowing side chain incorporation via olefin cross-metathesis. ${ }^{27,28}$ After considerable experimentation, the cross-metathesis with dicarbonate 7 required relatively forcing conditions (refluxing in benzene), due to the steric constraints imposed by the macrocycle. The resulting allylic carbonate $\mathbf{8}$ then allowed a $\pi$ allyl Stille cross-coupling with stannane 9 to afford the bis-acetonide protected natural product, which underwent a global deprotection to afford the first total synthesis of spirastrellolide A methyl ester (1). ${ }^{22}$ Notably, the 46-epi diastereomer of 1 showed distinctly different NMR spectra due to the influence of the proximate macrocycle.
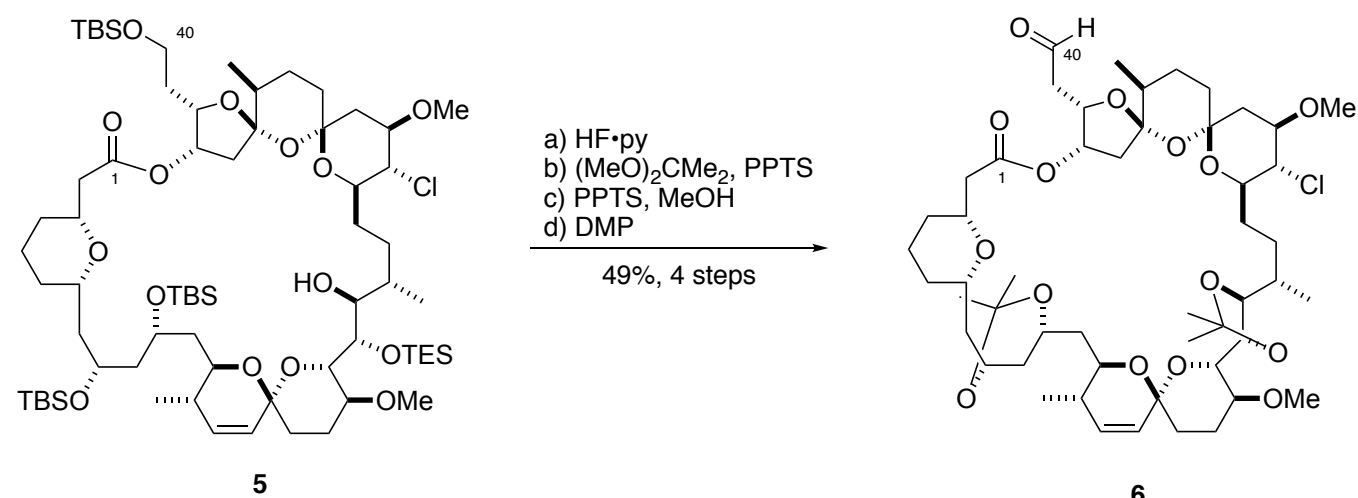

6

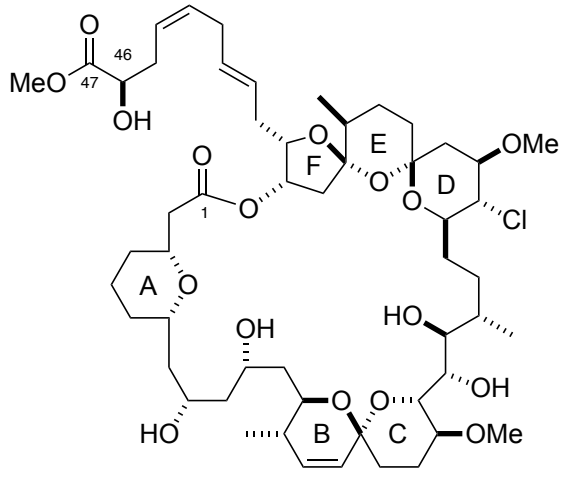

Spirastrellolide A methyl ester (1)

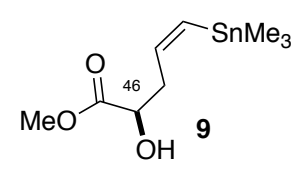

a) $\mathrm{PdCl}_{2}(\mathrm{MeCN})_{2}, 9$ b) PPTS, $\mathrm{MeOH}$

$52 \%, 2$ steps

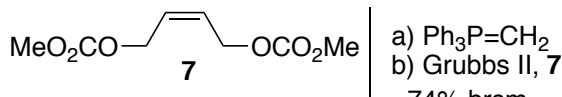
$74 \%$ brsm $E / Z 6: 1$

Scheme 1. Endgame sequence for the first-generation synthesis of spirastrellolide A methyl ester (1)

Having successfully completed the target molecule, and thereby validating the configurational assignment, we next sought to improve our synthesis, paying specific attention to avoiding unnecessary redox steps and protecting group manipulations. In particular, the 
need for a divergent side-chain installation strategy was now deemed unnecessary with the stereochemistry of the natural product now unambiguously assigned. Additionally, we sought to capitalise on the availability of key fragments from our first-generation approach, giving rise to the revised retrosynthetic analysis in Scheme 2. Notably, we looked to establish the 100 C1-C47 carbon backbone in $\mathbf{1 0}$ (from allylic carbonate $\mathbf{1 1}$ and stannane 12) in its entirety prior to macrolactonisation, thereby simplifying incorporation of the $(E, Z)$-skipped diene side chain. Building on earlier work, the BC spiroacetal moiety would be installed through PMB deprotection/in situ spiroacetalisation of a Z-enone arising from coupling of the C1-C16 alkyne fragment 13 and C17-C40 aldehyde $14 .^{26}$ Disconnection across C24-C25 via an $\mathrm{sp}^{3}$ -

$105 \mathrm{sp}^{2}$ Suzuki coupling ${ }^{29}$ then reveals two intermediates utilised previously, C17-C24 vinyl iodide $\mathbf{1 5}$ and C25-C40 bis-spiroacetal $16 .^{30}$ 


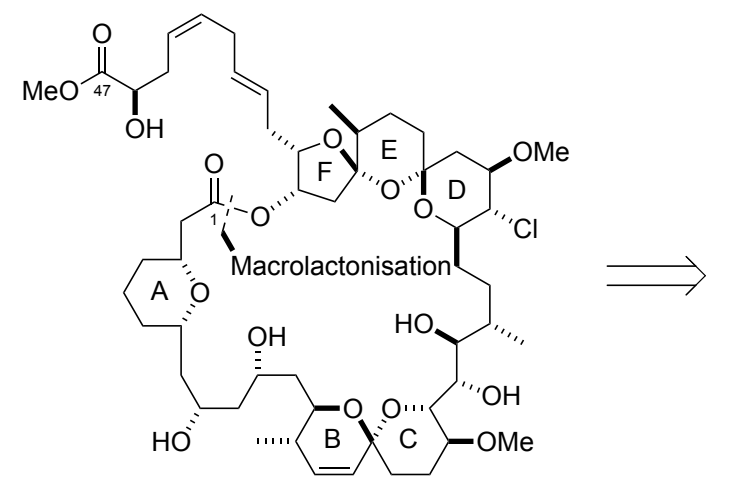

Spirastrellolide A methyl ester (1)
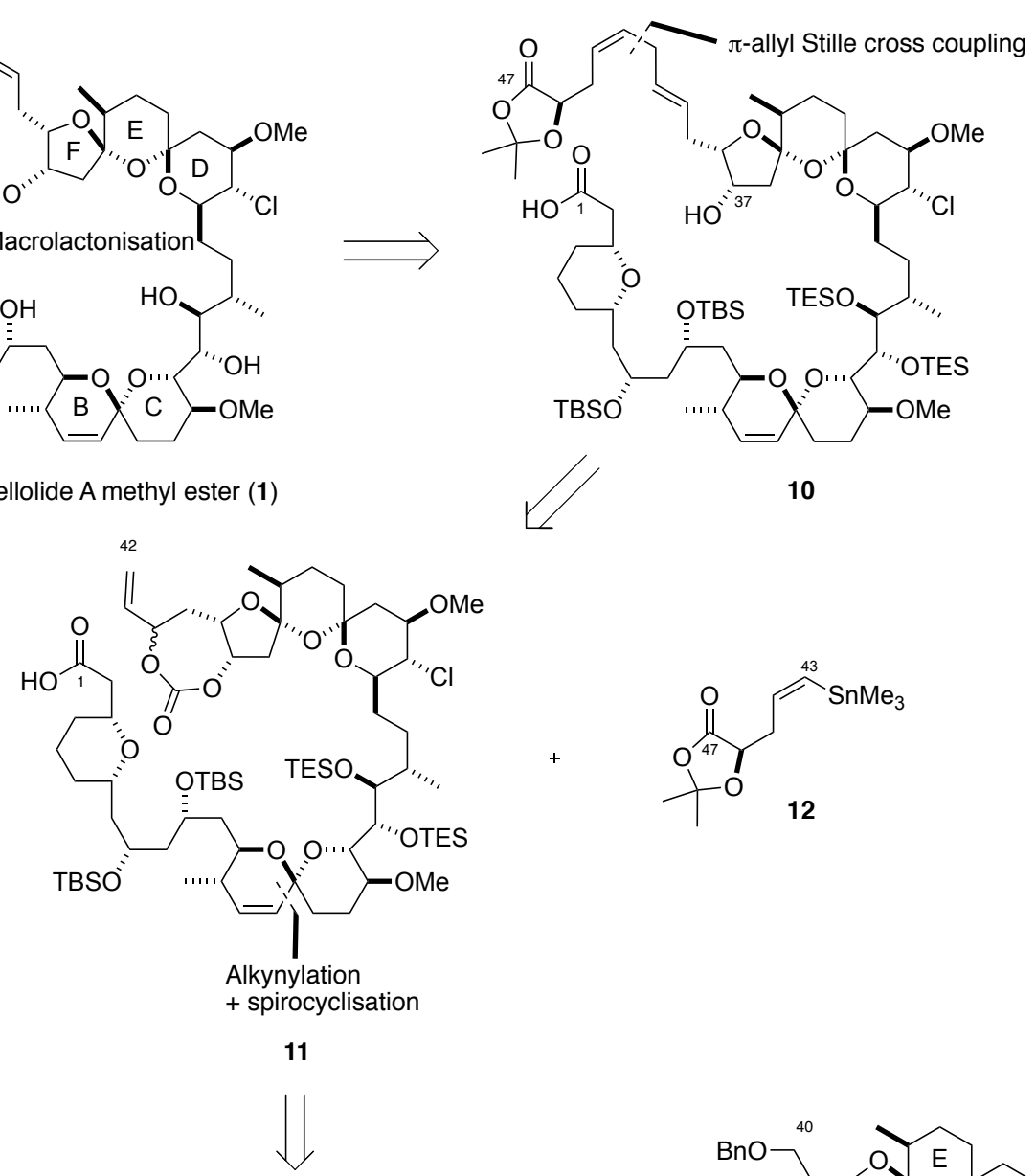

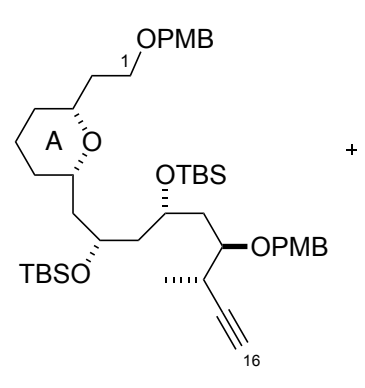

C1-C16 alkyne 13

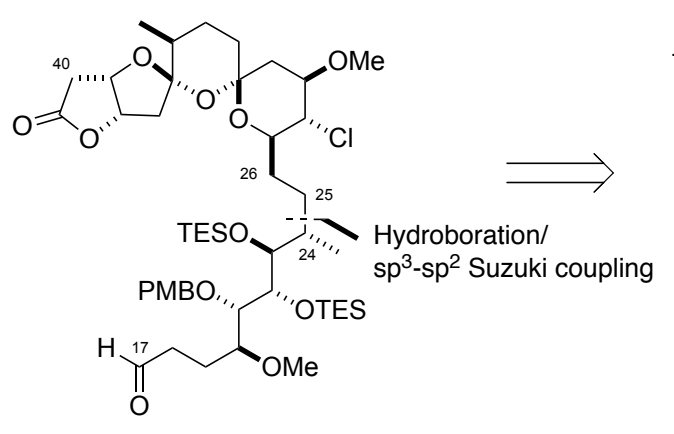

14
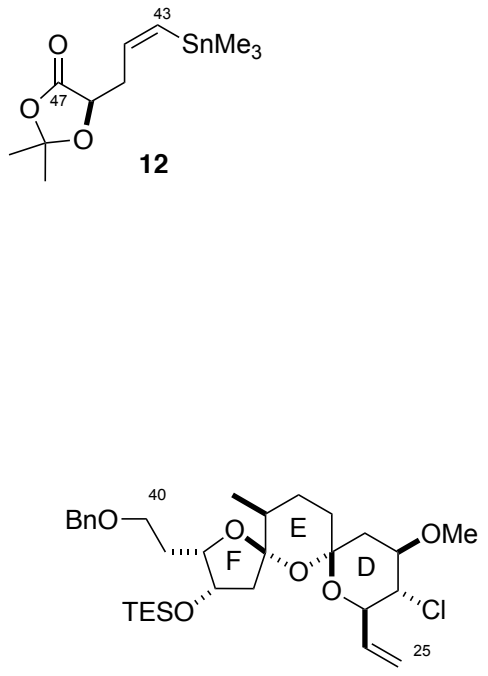

C25-C40 bis-spiroacetal 16

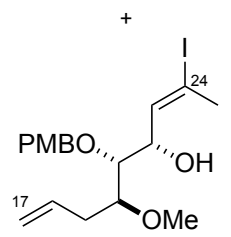

C17-C24 vinyl iodide 15

Scheme 2. Revised retrosynthesis of spirastrellolide A methyl ester (1)

In our first-generation synthesis, the construction of the C26-C40 DEF bis-spiroacetal

$110 \mathbf{1 7}$ via an acid-mediated deprotection/spiroacetalisation cascade of $\mathbf{1 8}$ was a major bottleneck. ${ }^{31}$ The problem stemmed from formation of the undesired furan 19 via competing elimination (Scheme 3A). Even after extensive optimisation, we could only generate a modest amount of the required C26-C40 DEF bis-spiroacetal 17. Thus, we needed to revise our strategy in order to achieve a reliable multigram supply of this essential fragment. Firstly, we 
115 removed the appended $\gamma$-lactone in a bid to avoid competitive furan formation. Additionally, we noted that the bis-spiroacetal could arise from a tetraol linear precursor. In particular, we recognised that the sense of asymmetric induction via the Sharpless asymmetric dihydroxylation required to install the $\mathrm{C} 37 / \mathrm{C} 38$ and $\mathrm{C} 26 / \mathrm{C} 27$ hydroxyls was the same. This led to an adventurous double dihydroxylation/spiroacetalisation cascade as in $\mathbf{2 0}$ to $\mathbf{2 1}$, which,

120 if successful, would provide an elegant and efficient synthesis of the DEF bis-spiroacetal ring system (Scheme 3B).

A)
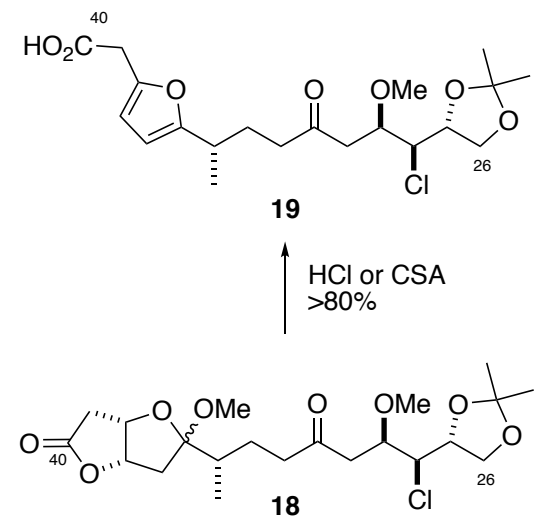

$\mid \begin{aligned} & \text { Dowex 50Wx8 } \\ & 40 \%\end{aligned}$

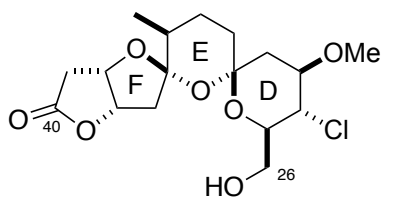

17
B)
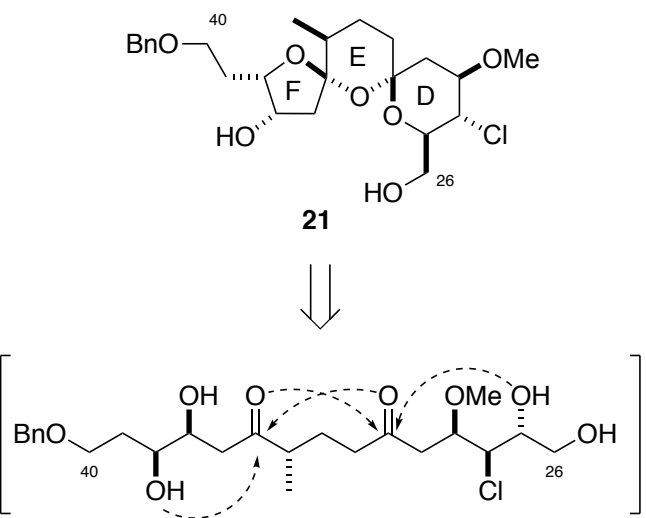

Double Sharpless asymmetric dihydroxylation/spiroacetalisation<smiles>C=CC(Cl)C(CC(=O)CC[C@@H](C)C(=O)CC=CCCOc1ccccc1)OC</smiles>

Scheme 3. A) First-generation approach towards the C26-C40 DEF bis-spiroacetal 17. B) Revised strategy towards

The required linear precursor $\mathbf{2 0}$ (Scheme 4) was readily prepared from aldehyde 22 and ketone 23, notably employing an Oehlschlager-Brown syn-choroallylation ${ }^{32}$ and our lactate aldol methodogy ${ }^{33}$ to set up the required stereocentres. ${ }^{24} \mathrm{~A}$ boron-mediated aldol reaction facilitated the fragment union to form $\beta$-hydroxyketone 24 , which led onto the required linear 130 precursor $\mathbf{2 0}$ via a four-step sequence. ${ }^{30}$ At this stage, we attempted the pivotal double 
asymmetric dihydroxylation. ${ }^{34}$ This initially afforded bis-hemiacetal $\mathbf{2 5}$, which to our delight spirocyclised under mild acidic conditions to afford the DEF-bis-spiroacetal 21. Fortuitously, we discovered that other spirocyclic isomers of $\mathbf{2 1}$ could be resubmitted under acidic conditions to afford the required DEF bis-spiroacetal cleanly. This was only made possible by

135 the increased stability of the DEF bis-spirocycle circumventing furan formation, giving us the opportunity to employ thermodynamic equilibration rather than kinetic control. A final bissilylation delivered the protected fragment 26 efficiently. Most importantly, this route facilitated a dependable multigram scale synthesis of the crucial C26-C40 bis-spiroacetal moiety. 

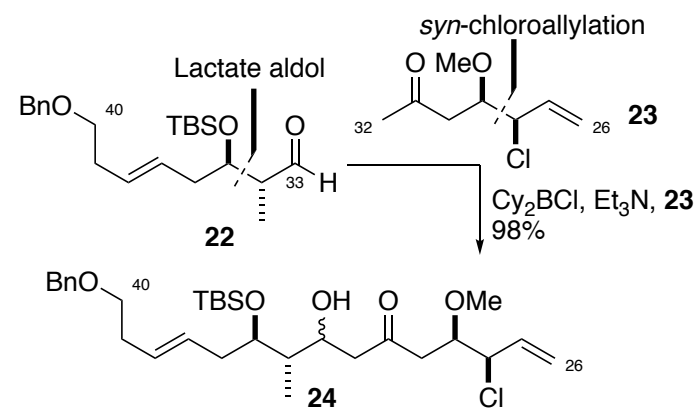

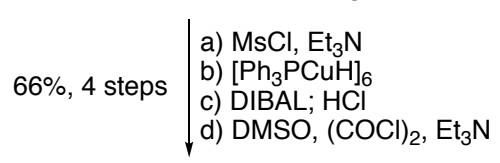

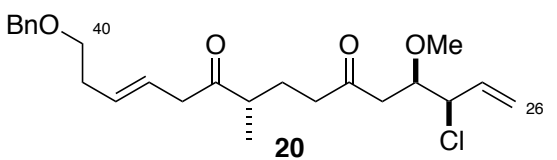

$\mid \begin{aligned} & \mathrm{K}_{2} \mathrm{OsO} \\ & \mathrm{K}_{3} \mathrm{Fe}(\mathrm{CN})_{6}\end{aligned}$

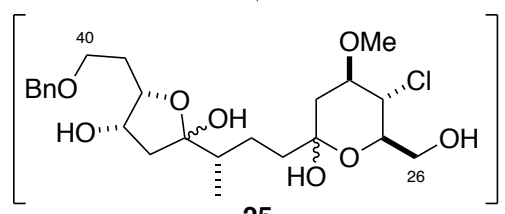

25

PPTS, MeOH

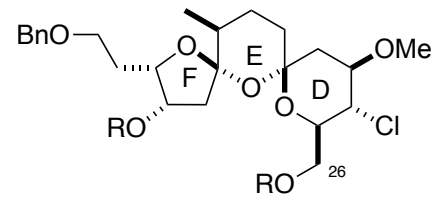

TESOTf $21: \mathrm{R}=\mathrm{H}+$ isomers (equilibrated to $\mathbf{2 1}$
by $26: \mathrm{R}=$ TES

$81 \%, 3$ steps

(2 recycles)

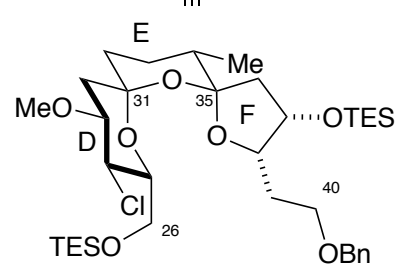

Scheme 4. Revised synthesis of the C26-C40 DEF bis-spiroacetal 26

Armed with an efficient and scalable route towards C1-C16 alkyne 13, C17-24 vinyl iodide 15 and now the C26-C40 bis-spiroacetal $\mathbf{2 6},{ }^{26,30}$ we set out to improve the fragment

145 coupling sequence (Scheme 5). ${ }^{35}$ Preparation of C17-C40 aldehyde 14 commenced with a primary TES deprotection, oxidation and methylenation to provide the corresponding $\mathrm{C} 25$ - 
C40 alkene 16. Hydroboration of $\mathbf{1 6}$ followed by an in situ $\mathrm{sp}^{3}-\mathrm{sp}^{2}$ Suzuki cross-coupling with vinyl iodide 15 forged the C24-C25 bond and furnished diene 27 cleanly. ${ }^{29,36}$ The final two stereocentres of the C17-C40 fragment were set up via a diastereoselective substrate-

150 controlled double hydroboration sequence; installing the C17 and C23 hydroxyl groups and affording the required 23,24-anti stereochemistry in 28. Protecting group manipulations then yielded an advanced triol, which was subjected to a selective triple oxidation of the two primary alcohols with concomitant lactonisation to afford the required C17-C40 aldehyde 14.

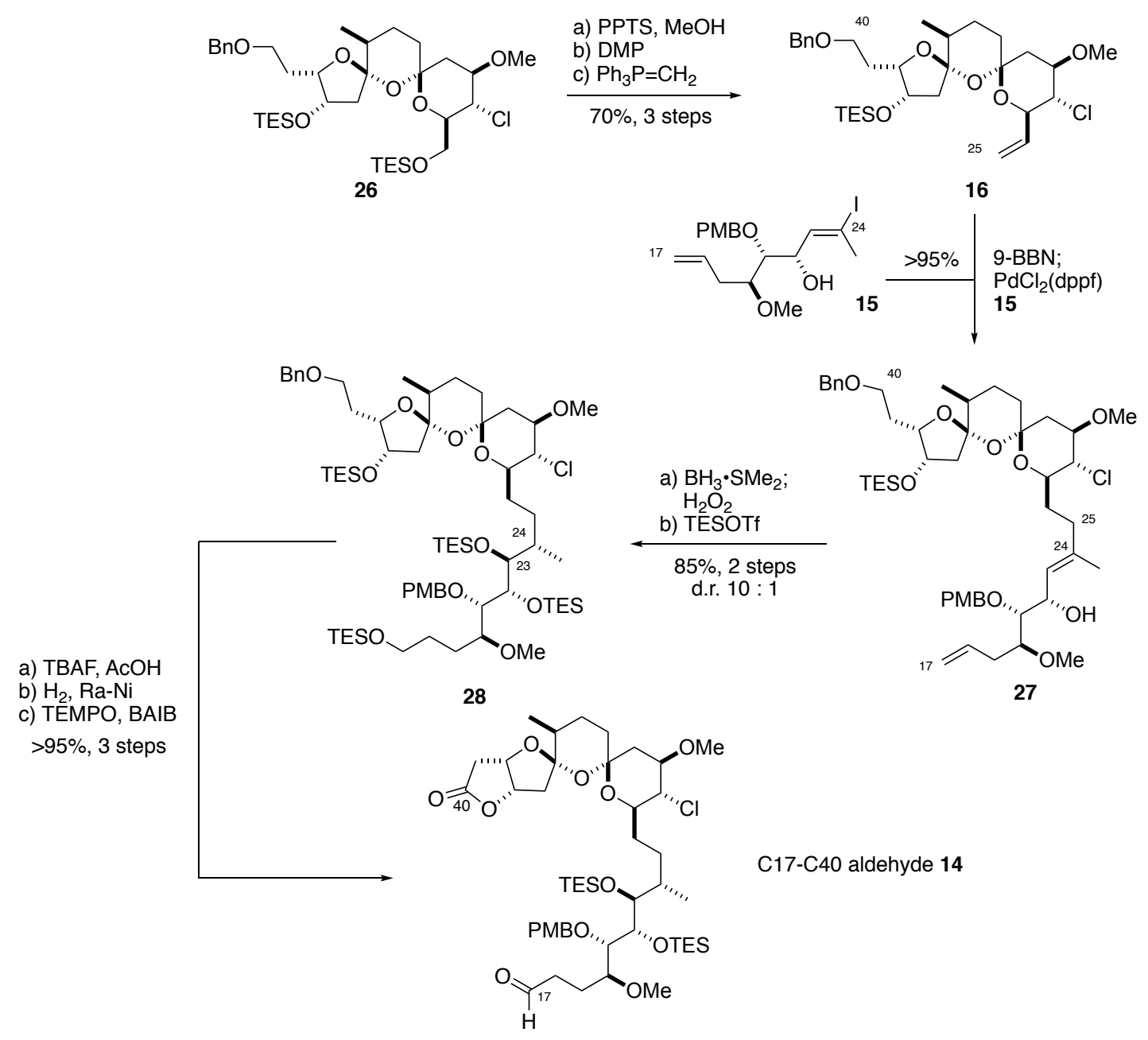

Scheme 5. Synthesis of the C17-C40 aldehyde 14

Our initial coupling strategy to form the C16-C17 bond hinged upon an the addition of an alkynyllithium species to the $\mathrm{C} 17$ aldehyde. ${ }^{26}$ However, this transformation now proved to 
160 be capricious owing to competing addition to the $\gamma$-lactone moiety. Instead, a Nozaki-HiyamaKishi coupling ${ }^{37,38}$ between iodoalkyne 29 and aldehyde 14, to our delight, chemoselectively and reliably forged the $\mathrm{C} 16-\mathrm{C} 17$ bond (Scheme 6). The BC spiroacetal formation commenced with a Lindlar reduction of the alkyne $\mathbf{3 0}$ and oxidation to the $Z$-enone. Subsequent bis-PMB deprotection under controlled conditions set the scene for a concomitant acetalisation to 165 cleanly forge the BC-spiroacetal ring system, now affording 31 with all the requisite $\mathrm{ABCDEF}$ rings in a stereodefined manner. With the carbon and oxygen skeleton for the macrocycle now in hand, our attention turned towards side chain installation and the final macrolactonisation. A selective primary TBS ether deprotection, partial reduction of the $\gamma$-lactone and vinylation afforded allylic alcohol 32, which was then treated with triphosgene to both temporarily mask 170 the diol as well as providing the requisite leaving group for the $\pi$-allyl Stille cross-coupling. Pleasingly, the planned cross-coupling between allylic carbonate $\mathbf{1 1}$ and vinyl stannane $\mathbf{1 2}$ proceeded efficiently, and was a major improvement over our previous cross-metathesis route in the presence of the full macrocycle. With only the macrolactonisation and global deprotection left, the finish line was now in sight. Once again, this transformation proved to 175 be significantly more challenging than initially anticipated! 


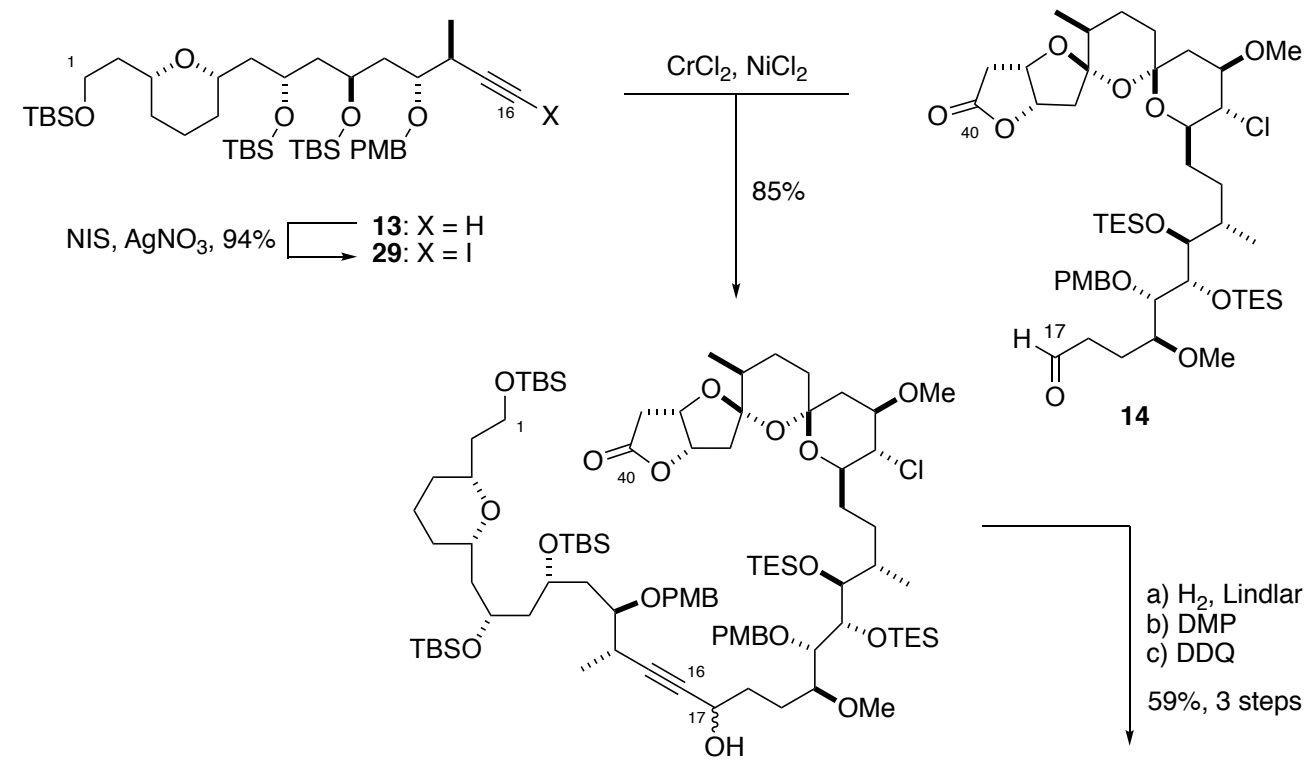

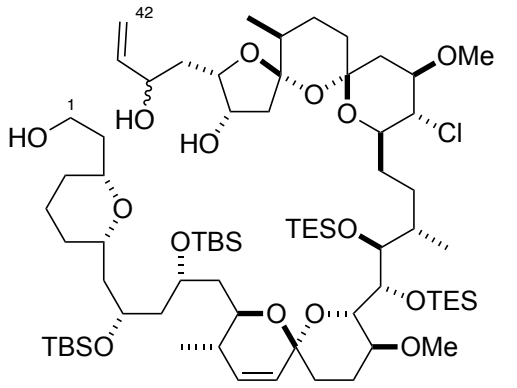

32

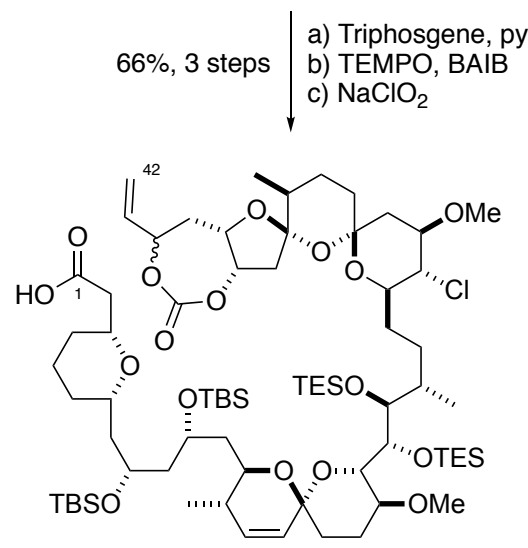

11

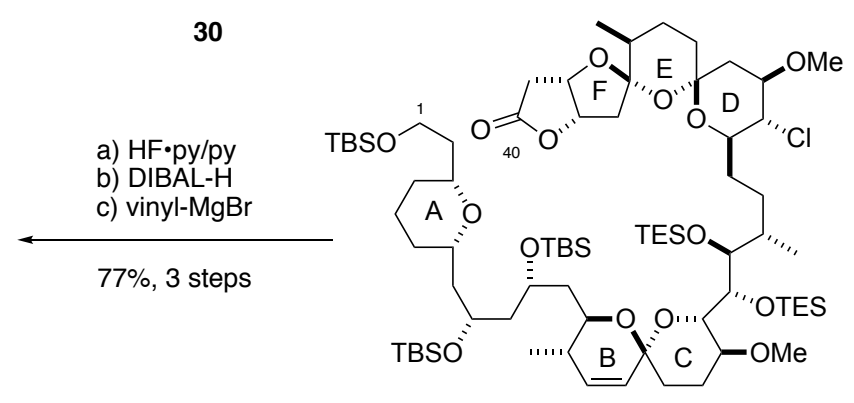

31

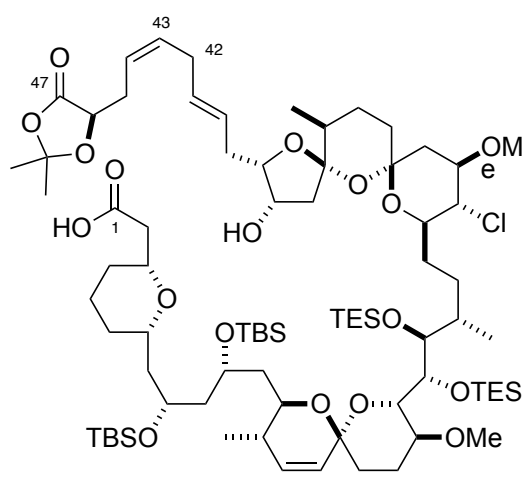

10

Scheme 6. Synthesis of the full C1-C47 carbon and oxygen skeleton of spirastrellolide A methyl ester 10

Frustratingly, subjecting seco-acid $\mathbf{1 0}$ to increasingly forcing conditions (including refluxing in toluene) for macrolactonisation ${ }^{39,40}$ not only failed to furnish the cyclised product, but returned degraded starting material. We initially surmised that the side chain was perhaps impeding the macrolactonisation, however, diol $\mathbf{3 3}$ corresponding to the truncated macrocycle also failed to cyclise when subjected to previously established macrolactonisation conditions 
(Scheme 7A). This unexpected difficulty was in stark contrast to the highly efficient macrolactonisation ( $>95 \%$ ) observed in our first-generation route (Scheme 7B), which we attributed to a degree of favourable conformational pre-organisation in the seco-acid $\mathbf{3 4}$. Comparison of the seco-acid 10 with that used previously highlighted only one seemingly minor structural difference - the (very distal) C23 TES ether. Therefore, we hypothesised that unfavourable conformational effects, presumably imposed by the additional silyl protecting group, were operating to bias the free acid away from ring closing with the $\mathrm{C} 37$ alcohol. As

190 such, we treated seco-acid 10 with PPTS in methanol to effect controlled mono- and bis-TES ether cleavage. Our hypothesis was proven to be correct; submitting either of the mono- or bisdesilylated products (35 and 36) to standard Yamaguchi macrolactonisation conditions now afforded macrocycles 37 and 38 in excellent yield (Scheme 7C). A final global deprotection completed our second-generation synthesis of spirastrellolide A methyl ester (1) in 23 linear 195 steps and 6\% overall yield from C26-C40 bis-spiroacetal 26. When compared with the firstgeneration synthesis ( 25 steps and $1 \%$ overall yield), it is pleasing to note the improvement in efficiency, both in terms of step count and yield. Moreover, we discovered that we were incredibly lucky in our first-generation synthesis - where the troublesome C23-TES ether was unintentionally cleaved in the BC-spiroacetalisation step, which greatly assisted the crucial downstream macrolactonisation reaction. An important lesson was learned here, that protecting groups can have subtle and unpredictable conformational effects in such complex substrates! 
A)

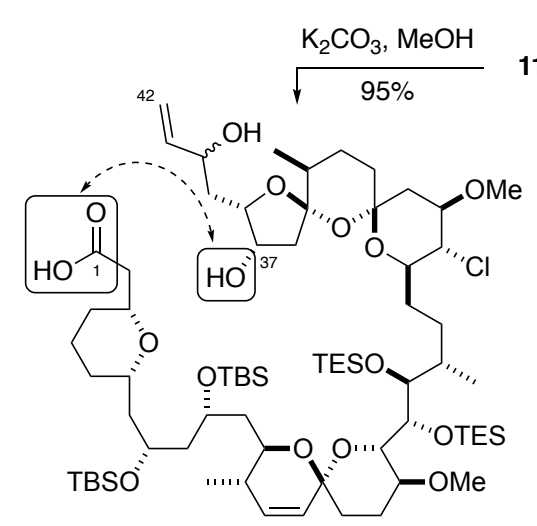

33

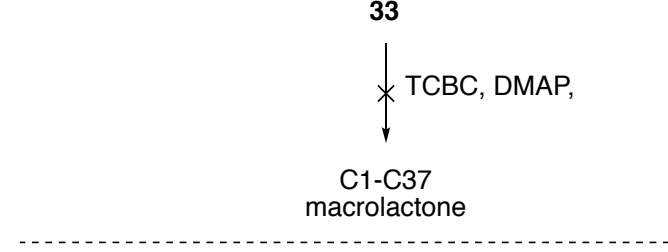

B)

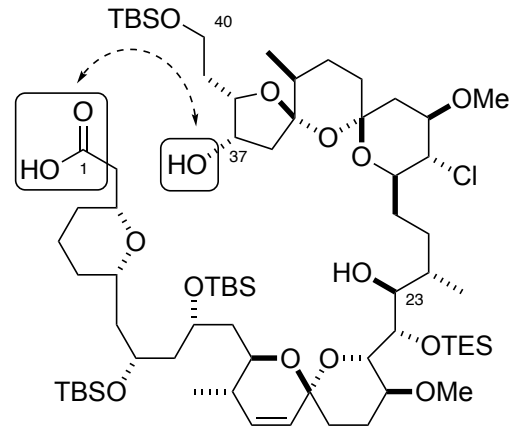

34

TCBC, DMAP,

C1-C37

macrolactone (5)
C)
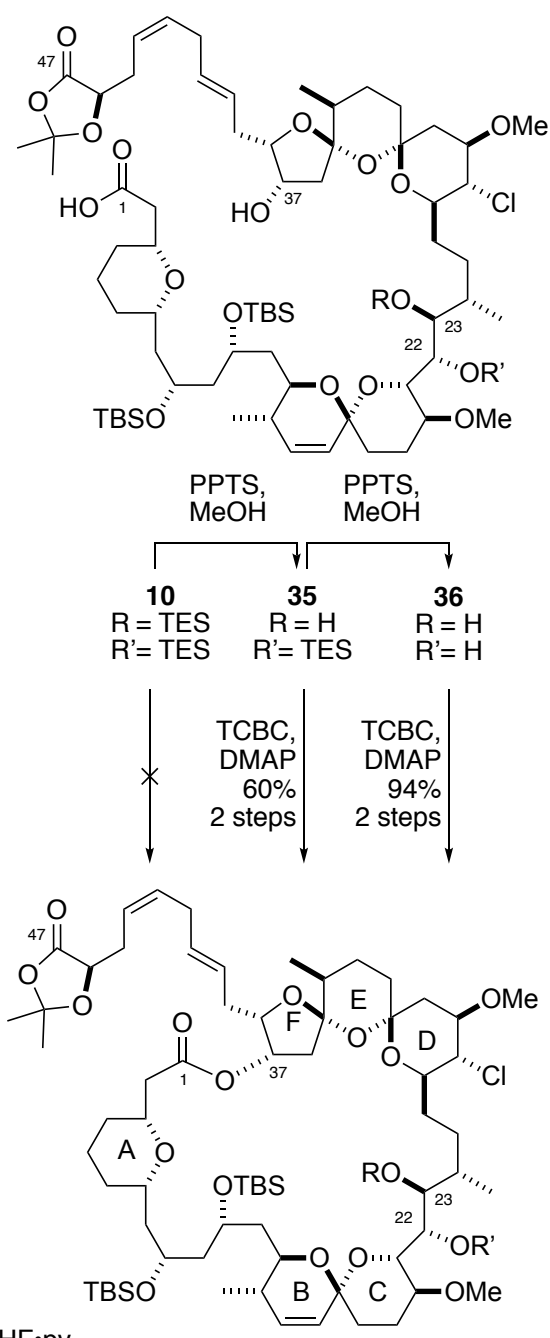

a) HF-py

b) $\mathrm{K}_{2} \mathrm{CO}_{3}, \mathrm{MeOH}$ 37: $\mathrm{R}=\mathrm{H}, \mathrm{R}^{\prime}=\mathrm{TES}$

$55 \%, 2$ steps

Spirastrellolide A methyl ester (1)

Scheme 7. A) Truncated seco-acid 33 failed to macrocyclise when subjected to established macrolactonisation conditions B) Macrocyclisation conditions in our first-generation synthesis C) Endgame 


\section{Leiodermatolide}

In 2008, leiodermatolide (2) was isolated from the lithistid sponge Leiodermatium sp. collected off the coast of Florida by the Wright group. ${ }^{41}$ Spectroscopic analysis illuminated the planar structure of $\mathbf{2}$ and revealed a 16-membered macrolactone containing a $Z, Z$-diene and a pendant carbamate group, as well as an $E, E$-diene on the side chain terminating in a $\delta$ -

215 lactone. The assigned structure highlighted the presence of nine stereocentres; six of which lie in the macrocycle and three in the terminal $\delta$-lactone. ${ }^{42}$ Biological evaluation showed that leiodermatolide exhibited potent anticancer activity, in particular against a range of drugresistant cancer cell lines. While leiodermatolide-treated cells exhibited physiological responses often typified by tubulin-binding compounds, in vitro studies failed to show

220 evidence for any direct tubulin interaction. As such, it was suggested that leiodermatolide acted via an indirect mechanism orthogonal to other known tubulin-targeting anticancer drugs, indicative of a promising anticancer drug candidate.

Our involvement with leiodermatolide was borne from its initially inconclusive stereochemical assignment. In collaboration with the Wright group, extensive NMR spectroscopic analysis, molecular modelling and computational DP4 NMR predictions ${ }^{43}$ allowed us to refine the structure to a single diastereomer for the $\mathrm{C} 1-\mathrm{C} 16$ macrocycle and the C21-C25 $\delta$-lactone with $>99 \%$ probability. Unfortunately, the distal nature of the C21-C25 $\delta$ lactone relative to the macrocycle precluded a conclusive determination of the stereochemistry between these two stereoclusters, leading to four candidate stereoisomers for the natural 230 product. To definitively pin down the stereochemistry of $\mathbf{2}$, we embarked on a synthetic campaign geared towards confirming the 3D structure of the macrocycle followed by the full natural product. A synthesis-enabled stereochemical elucidation was a notion shared with other research groups, ${ }^{44,45}$ which, to date, has resulted in one other group successfully synthesising leiodermatolide. ${ }^{46,47}$ 
As the absolute configuration was unknown, we arbitrarily targeted ent-2 and its diastereomer for initial studies. Our initial approach towards 2 hinged upon a late-stage sp $^{2}$ $\mathrm{sp}^{2}$ Suzuki coupling across $\mathrm{C} 17-\mathrm{C} 18$ to allow the flexible appendage of both enantiomers of the C18-C25 $\delta$-lactone to the macrocycle, as shown in Scheme 8A. The C18-C25 $\delta$-lactone 39 could be readily synthesised from either enantiomer of $\mathbf{4 0}$. We anticipated that the $\mathrm{C} 1-\mathrm{C} 17$

240 macrocycle 41 could be constructed from a linchpin bis-halide fragment $\mathbf{4 2}$, leveraging the more reactive vinyl iodide to selectively engage in a Stille cross-coupling with C1-C11 vinyl stannane 43.

In executing this approach (Scheme 8B), we discovered that the bis-TBS protection of the C7 and C9 hydroxyl groups required relatively forcing conditions to effect the second 245 silylation at $\mathrm{C} 7 .^{48}$ This observation indicated the possibility of realising a site-selective C9 carbamate installation in the endgame. Our resulting synthesis of the $\mathrm{C} 1-\mathrm{C} 17$ macrocycle 41 confirmed our relative stereochemical assignment through spectroscopic correlations. ${ }^{48}$ However, the specific rotation recorded for the macrocycle was opposite in sign to (-)leiodermatolide; tentatively suggesting that we may have embarked in the wrong enantiomeric 250 series. Additionally, there were two key issues we needed to address in the evolution of our synthetic strategy. Firstly, while the semi-reduction of vinyl dibromide 44 to (Z)-vinyl bromide $\mathbf{4 5}$ proceeded smoothly, subsequent attempts at converting it into the vinyl stannane proved problematic. This involved cleavage of the C7 and C9-TBS ethers to afford diol 46, followed by stannylation under Wulff-Stille conditions ${ }^{49}$ to form stannane 43 , albeit in a 255 modest yield (Scheme 6B). Furthermore, despite preliminary results suggesting otherwise, our vision of a late-stage site-selective carbamate installation proved unrewarding; treatment of the macrocycle 47 with trichloroacetyl isocyanate ${ }^{50}$ resulted in a $3: 2$ mixture of regioisomeric products $\mathbf{4 1}$ and $\mathbf{4 8}$ that favoured the undesired C7 carbamate $\mathbf{4 8}$. Moreover, attempts at realising the key Suzuki coupling to afford the full leiodermatolide carbon skeleton 
260 proved fruitless; vinyl bromide 41 was found to be unreactive under a variety of palladiumcatalysed conditions. $^{51}$

A)

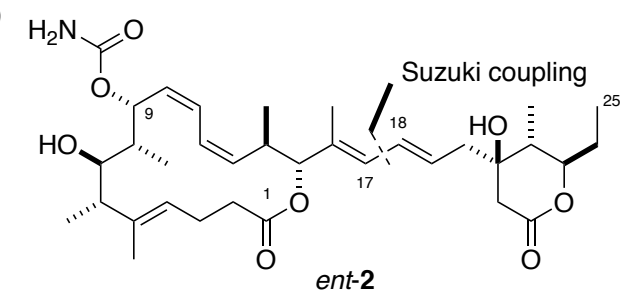

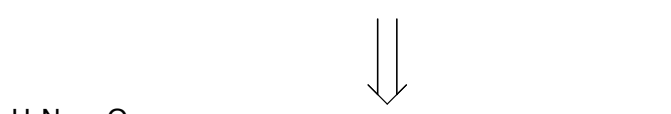

$\mathrm{H}_{2} \mathrm{~N} Y \mathrm{O} \quad$ Stille coupling

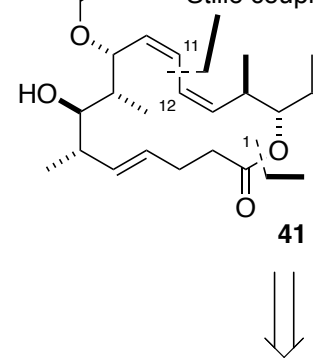<smiles>CCCCC(C)=CCCC(C)=O</smiles>

43

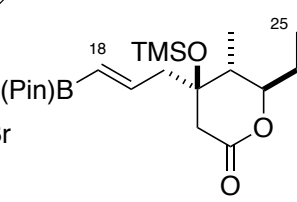

39
41<smiles>C1CCCCC1</smiles>

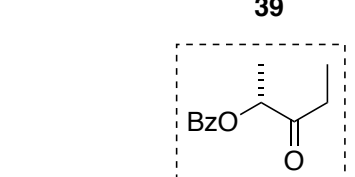

40

Scheme 8. A) Initial approach towards leiodermatolide (ent-2). B) Summary of our first-generation synthesis towards the C1-C17 macrocycle 41

This intelligence gathering exercise prompted us to revise our synthetic strategy towards 2, as highlighted in Scheme 9, and we instead looked towards forming the fully elaborated macrocycle via a late-stage macrolactonisation. As the $\mathrm{C} 11-\mathrm{C} 12$ bond was reliably installed via a Stille coupling, we sought to disconnect the molecule into the C1-C11 vinyl stannane ent-43 and the $\mathrm{C} 12-\mathrm{C} 25 \delta$-lactone 49. The $\mathrm{C} 12-\mathrm{C} 25$ fragment itself can then be constructed

270 from vinyl iodide $\mathbf{5 0}$ and $\delta$-lactone ent-39, employing a Suzuki coupling to forge the C17-C18 bond. Despite disappointing initial results, we remained optimistic about effecting a regioselective carbamate formation, thereby minimising protecting group manipulations. 


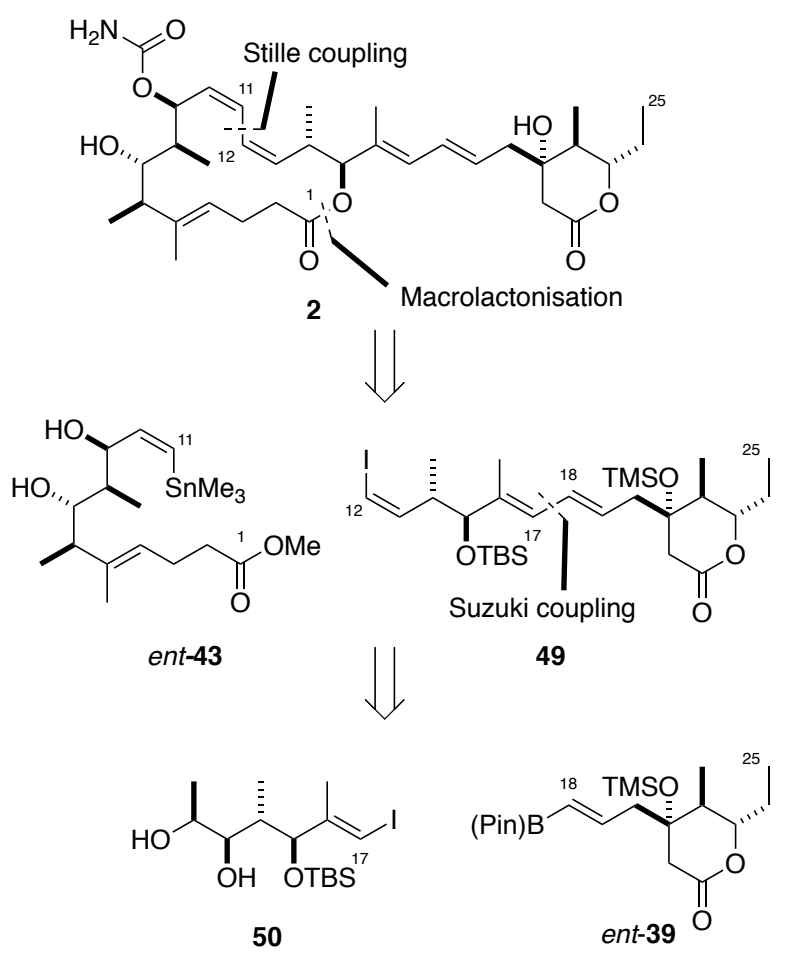

Scheme 9. Revised retrosynthesis for leiodermatolide (2)

Our revised synthesis of the C1-C11 stannane ent-43 commenced from the Weinreb amide 51 derived from $(R)$-Roche ester (Scheme 10). By trapping the kinetic $Z$-enolate of the derived ketone with Comins' reagent ${ }^{52}$ followed by a Suzuki-type methylation of vinyl triflate 52, we successfully formed the trisubstituted alkene $53 .{ }^{53}$ Employing methodology developed 280 by our group, a lactate aldol reaction between $(R)$-lactate-derived ethyl ketone $(R)-\mathbf{4 0}$ and aldehyde $\mathbf{5 4}$ readily afforded the required anti adduct $\mathbf{5 5}$ with excellent diastereoselectivity. ${ }^{33,54,55}$ A four-step sequence installed the requisite alkyne and removed the lactate auxiliary. The required 1,3-anti reduction on ynone $\mathbf{5 6}$ proved problematic; employing the Evans-Tishchenko ${ }^{56}$ protocol failed outright. Unfortunately, the Evans-Saksena 285 reduction $^{57}$ on the same substrate gave poor diastereoselectivity. This was rationalised based on the small size of the alkyne substituent, reducing its preference to occupy the equatorial position in the transition state. Based on this hypothesis, we looked towards increasing the steric bulk by preparing the $Z$-vinyl iodide $57^{58}$. Luckily, this drastically improved the 
selectivity of the 1,3-anti reduction via the Evans-Saksena protocol, completing the required 290 stereotetrad in the C1-C11 fragment. Next, lithiation followed by trapping with tributyltin chloride proceeded smoothly to give the C1-C11 stannane 58. Gratifyingly, this route was a significant improvement over our initial approach (20\% yield over 14 steps, versus $6 \%$ yield over 14 steps). ${ }^{48,59}$
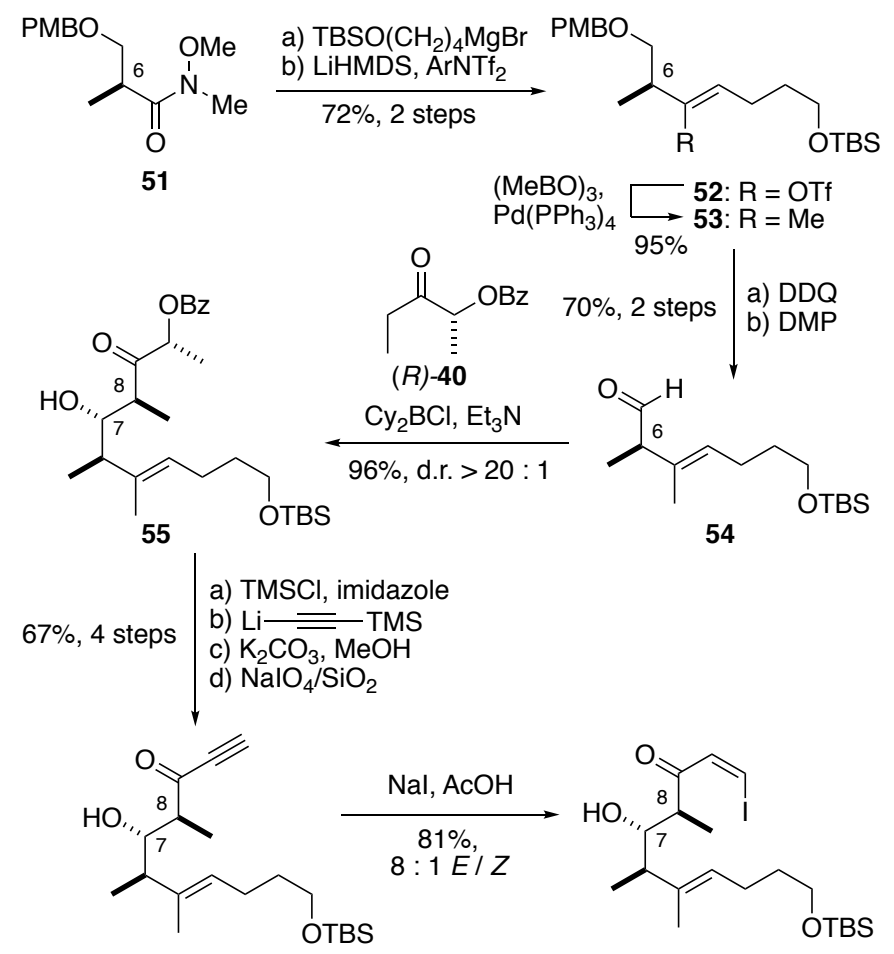

56

57

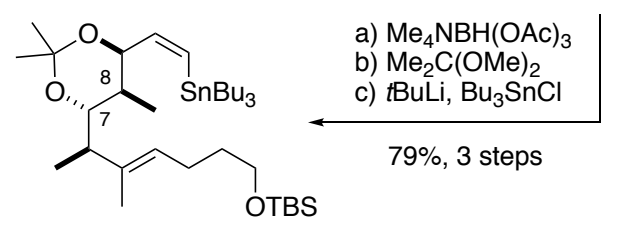

58

Scheme 10. Synthesis of the C1-C11 vinyl stannane $\mathbf{5 8}$

The C12-C17 vinyl iodide was constructed again using our lactate aldol methodology, furnishing $\mathbf{5 0}$ in four steps (via aldol adduct 59) from ethyl ketone $(S)-\mathbf{4 0}$ (Scheme 11). ${ }^{33,54,55}$ Synthesis of the C18-C25 $\delta$-lactone commenced with a boron-mediated aldol reaction 300 between ketone $(R)-\mathbf{4 0}$ and propanal, affording the required anti adduct $\mathbf{6 0}$. The $\delta$-lactone was constructed through a $\mathrm{BF}_{3} \cdot \mathrm{OEt}_{2}$-mediated Mukaiyama aldol reaction between ketone $\mathbf{6 1}$ and 
silyl ketene acetal $\mathbf{6 2} .^{8,60}$ This, followed by an acid-mediated lactonisation, delivered the $\delta$ lactone 63, where the matched stereoinduction from 1,2-Felkin and 1,3-Evans polar models are mutually reinforcing. ${ }^{61}$ Subsequent silylation afforded the protected lactone $\mathbf{6 4}$, where a 305 two-step sequence revealed the required vinyl boronate ent-39 in anticipation for the key cross-coupling.

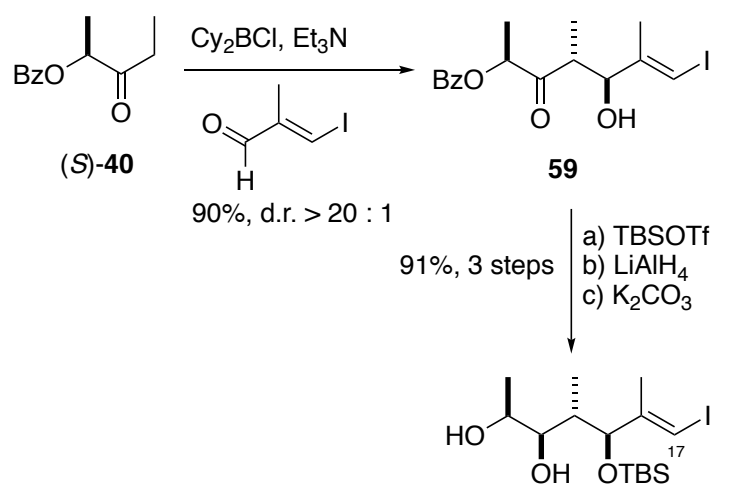

50
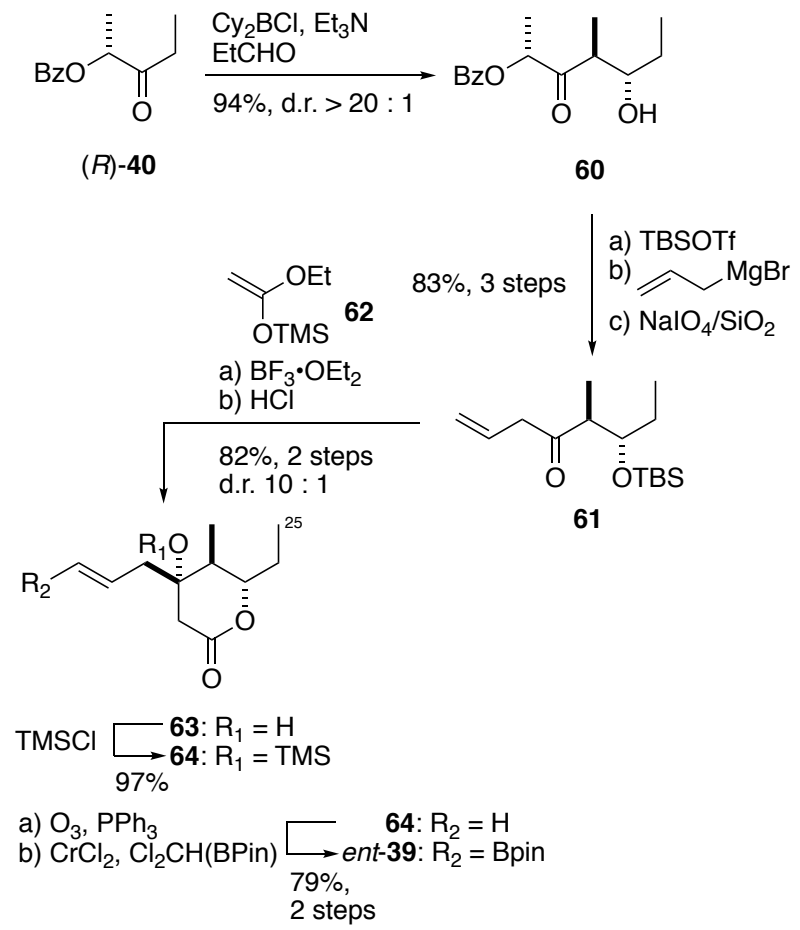

Scheme 11. Synthesis of the C12-C17 vinyl iodide $\mathbf{5 0}$ and C18-C25 $\delta$-lactone ent-39

The planned Suzuki coupling could be effected between vinyl iodide $\mathbf{5 0}$ and vinyl boronate ent-39. Advantageously, we discovered that the fragment union could also be readily 
achieved with excellent geometrical control via the Heck reaction to deliver 65 (Scheme 12), ${ }^{62}$ saving two steps in converting the alkene 64 to the vinyl boronate ent-39 (vide supra). A twostep procedure revealed the required C12-C25 vinyl iodide 49, which underwent a facile Stille

315 coupling ${ }^{63,64}$ with stannane $\mathbf{5 8}$ to establish $\mathbf{6 6}$, corresponding to the full carbon skeleton of leiodermatolide. Finally, a series of redox and protecting group manipulations revealed the seco-acid 67, which was efficiently macrocyclised under our preferred Yamaguchi conditions $^{39}$ to generate the 16-membered macrolactone.

With a global deprotection revealing the des-carbamoyl derivative of leiodermatolide

$320 \mathbf{6 8}$, all that was required was the pivotal regioselective C9 carbamoylation. We surmised that the steric hindrance around $\mathrm{C} 7$ should heighten the reactivity of the $\mathrm{C} 9$ alcohol, a rationale supported by molecular modelling studies. As previously alluded to, treating the truncated macrolactone 47 with trichloroacetyl isocyanate ${ }^{50}$ favoured the formation of the undesired $\mathrm{C} 7$ carbamate 48, with extensive experimentation failing to overturn this result. Interestingly 325 enough, we observed that esterification or silylation proceeded with high selectivity at the C9 position. This hinted that it was indeed the more reactive position, with the carbamoylating agent behaving anomalously. Leveraging this finding, a sequence involving bis-silylation, selective C9 desilylation, followed by treatment with trichloroacetyl chloride and C7 desilylation successfully led to (-)-leiodermatolide (2) in 23 steps and 3.2\% overall yield. ${ }^{59}$

330 Careful comparison with the authentic sample provided by the Wright group confirmed that they were identical in all respects. Serendipitously, this 3D structure corresponds exactly to the one out of four stereoisomers arbitrarily rendered in our isolation paper. ${ }^{42}$ At this point, we could embark on a programme of SAR studies and further biological evaluation of this promising anticancer lead structure. ${ }^{65}$ 


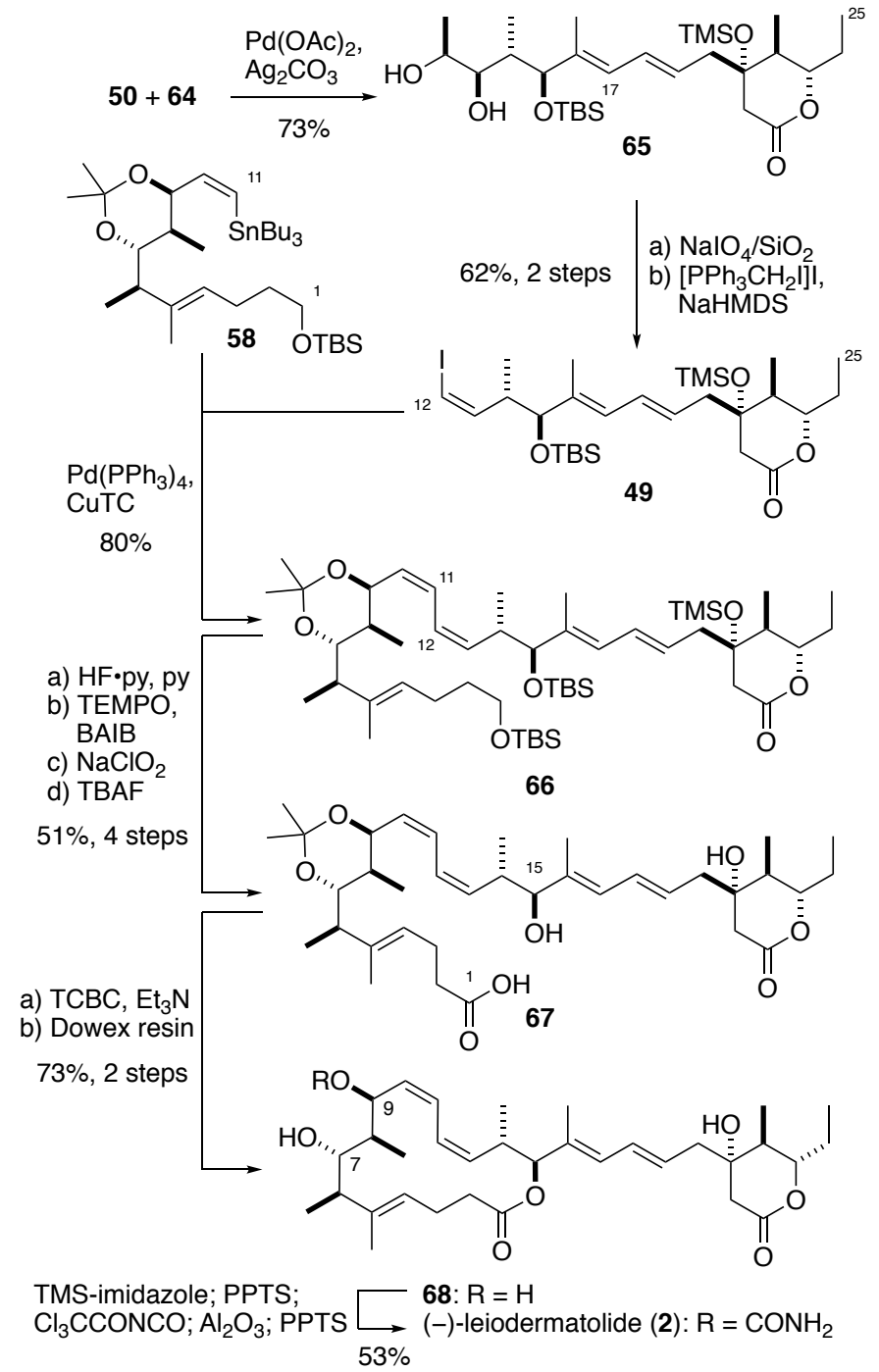

Scheme 12. Fragment union and completion of (-)-leiodermatolide (2) 


\section{Rhizopodin}

Rhizopodin (3) is an architecturally complex macrocyclic polyketide first isolated in 1993 by Höfle and Reichenbach from the myxobacterium Myxococcus stipitatus. ${ }^{66}$ By binding with and inhibiting actin polymerisation, rhizopodin mediates potent antiproliferative activity as well as strong cytostatic effects against a range of cancer cell lines. ${ }^{67}$ This selective interaction with actin also enabled its structural elucidation, with X-ray crystallographic

345 studies of the bound rhizopodin-actin complex revealing an intriguing $C_{2}$-symmetric macrodiolide. ${ }^{68}$ From a structural perspective, 14 of the 18 stereocentres are embedded in the 38-membered macrolide core, together with two oxazole rings and two diene motifs, with the remaining four stereocentres located on the two side chains. ${ }^{69}$ The ornate architecture and promising anticancer profile of rhizopodin has rendered intensive research towards its total

350 synthesis. Although several groups have reported the synthesis of various substructures, ${ }^{70-74}$ there has only been two completed total syntheses of the target structure itself. ${ }^{75-77}$

Our proposed synthesis (Scheme 13) of rhizopodin (3) centred on structural simplification into the truncated monomer 69 and known side chain fragment $70{ }^{78}$ This disconnection provided a degree of flexibility, with macrocycle formation possible via direct

355 or sequential esterification, followed by bidirectional aldol coupling with ketone $\mathbf{7 0}$ to incorporate the requisite side chain(s). Oxazole formation was envisaged via amide bond formation between C14-C22 acid 71 and C8-C13 amino alcohol $\mathbf{7 2}$ followed by dehydration, while diene installation was proposed using a Stille coupling of vinyl iodide $\mathbf{7 3}$ and a suitable C8 stannane.

360 As is often the case with complex polyketide synthesis, the strategic incorporation of orthogonal protecting groups was of crucial importance. Initially, we envisaged incorporating PMB ethers to chemoselectively unmask the required alcohols for the macrolactonisation and side chain attachment. However, we found that an oxidative PMB ether cleavage using DDQ 
resulted in the concomitant oxidation of the C5 allylic methyl ether, with alternative Lewis 365 acidic cleavage degrading our advanced intermediates. ${ }^{77}$ As such, we opted for a carefully selected combination of silyl protecting groups. Notably, attempts at deprotecting the C16OTBS ethers in the endgame resulted solely in eliminated product. Frustratingly also, attempts at deprotecting a primary C22-OTIPS ether to allow side-chain installation, in the presence of a secondary C16-OTES ether, resulted in simultaneous cleavage of both silyl groups. These difficulties ultimately forced us to opt for a riskier gamut of silyl protecting groups in acid $\mathbf{7 1}$ and aldehyde $\mathbf{7 3}$ (vide infra).

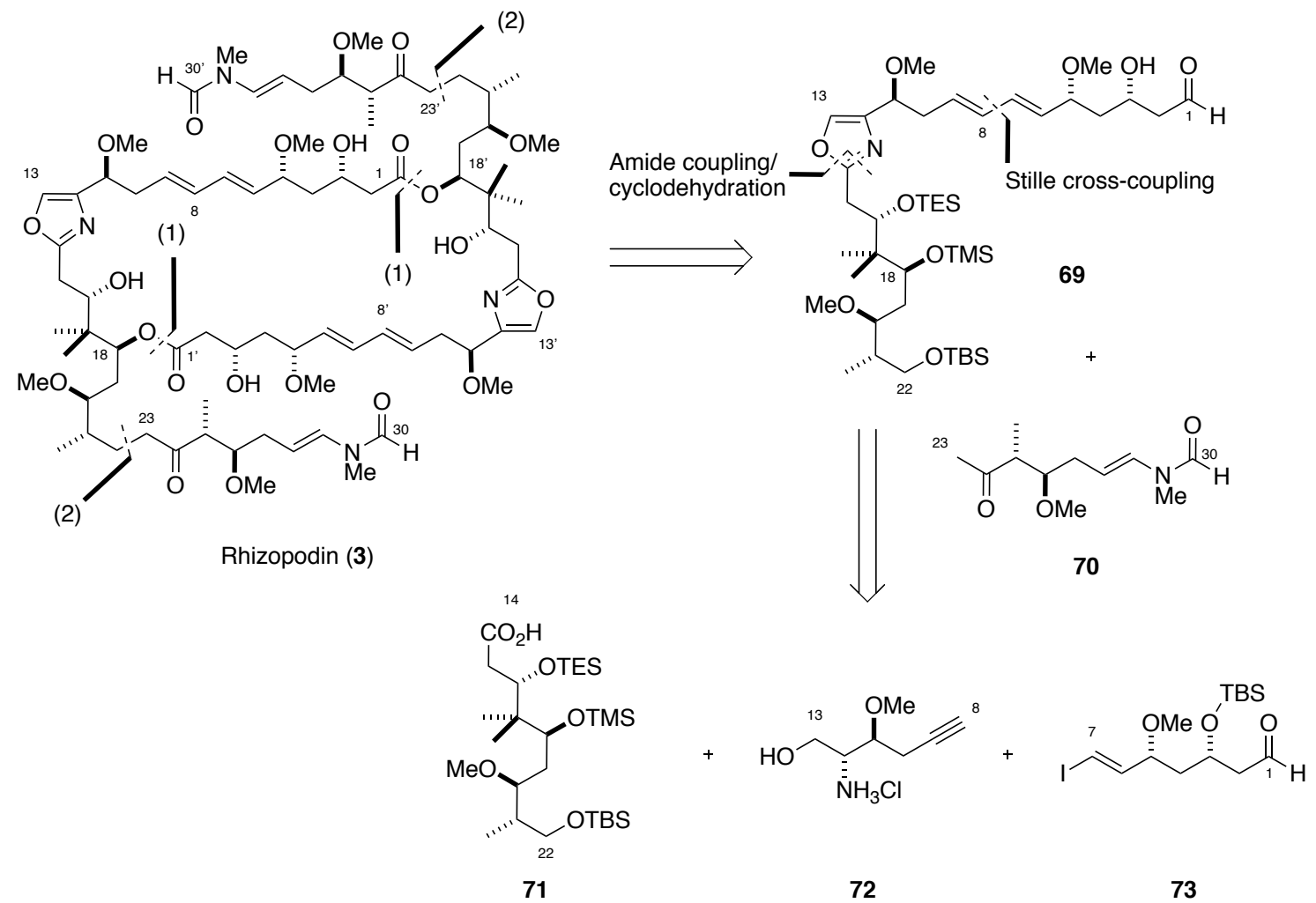

Scheme 13. Retrosynthetic analysis of rhizopodin (3). Disconnection (1) refers to an esterification/macrolactonisation, disconnection (2) refers to an aldol/dehydration/reduction sequence

Synthesis of the C14-C22 carboxylic acid 71 commenced with a Brown allylation onto Roche ester-derived aldehyde 74 (Scheme 14A). ${ }^{79}$ The remaining stereocentres in this fragment were generated first via a Mukaiyama aldol reaction between aldehyde $\mathbf{7 5}$ and silyl ketene acetal 76, setting up the C18 stereocentre, and a subsequent diastereoselective reduction ${ }^{80}$ of the cyclic ketone after methanolysis of dioxinone 77. From $\beta$-hydroxylactone 
380 78, subsequent protections and oxidation afforded the C14-C22 acid 71. The amino-alcohol coupling partner $\mathbf{7 2}$ required for the oxazole formation was formed from propargyl alcohol 79 (Scheme 14B). A Sharpless asymmetric epoxidation (yielding epoxide 80 ${ }^{81,82}$ followed by amidation and regioselective epoxide opening gave oxazoline 81. A final sequence of methylation and hydrolysis then delivered the amino alcohol $\mathbf{7 2 .}$

The final $\mathrm{C} 1-\mathrm{C} 7$ fragment $\mathbf{7 3}$ required for the macrocycle was obtained by an enantioselective Mukaiyama aldol reaction between aldehyde 82 and Chan's diene (83) (Scheme 14C). ${ }^{83,84}$ Subsequent methanolysis of dioxinone 84 followed by a Narasaka reduction $^{85}$ generated the free diol. Protecting group manipulations and a final methylation of the free $\mathrm{C} 5-\mathrm{OH}$ then afforded the required Stille coupling partner $\mathbf{7 3}$. 
A) a) $(-)-\mid p c_{2}$ Bally|

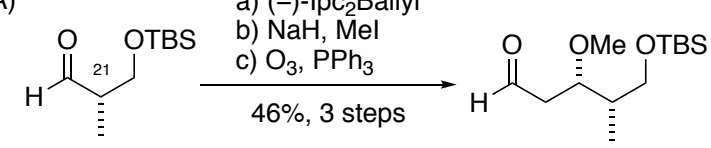

74

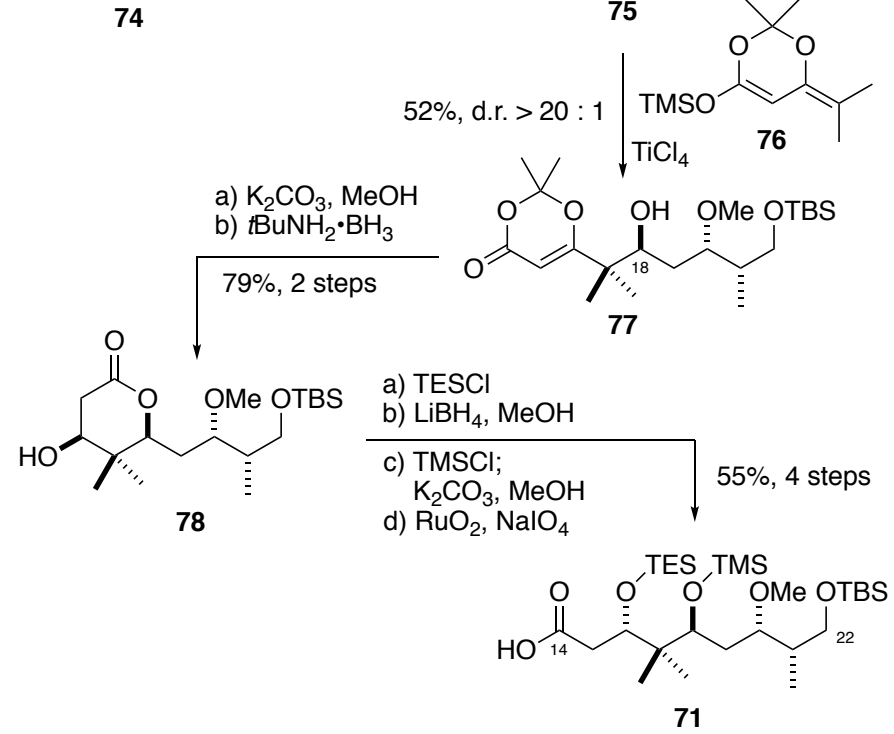

B)

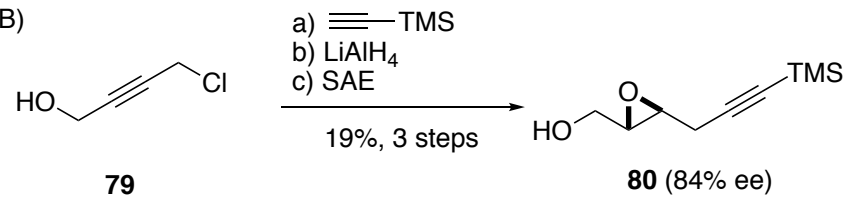

\begin{tabular}{l|l}
$69 \%, 3$ steps & $\begin{array}{l}\text { a) } \mathrm{Cl}_{3} \mathrm{CCN}, \mathrm{DBU} \\
\text { b) } \mathrm{Me}_{2} \mathrm{AICl} \\
\text { c) TBAF }\end{array}$
\end{tabular}

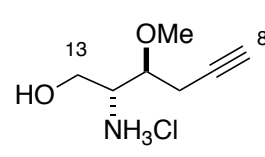

72
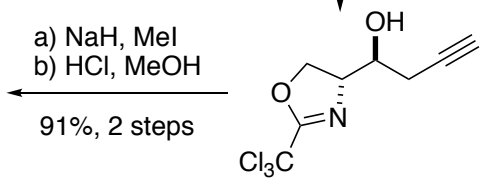

$81(96 \%$ ee $)$

C)<smiles>C=C1C=C(O[Na])OC(C)(C)O1</smiles>

83

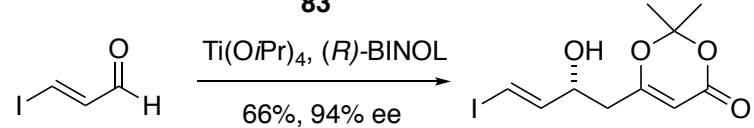

82

84

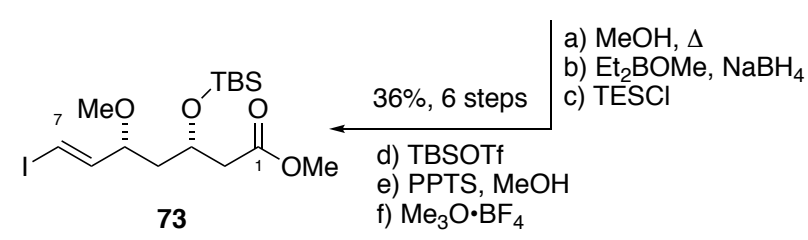

Scheme 14. A) Synthesis of the C14-C22 carboxylic acid 71. B) Synthesis of the C8-C13 amino alcohol 72. C) Synthesis of the C1-C7 vinyl iodide $\mathbf{7 3}$ 
Fragment assembly commenced with an amide bond formation between carboxylic acid

39571 and amino alcohol 72 (Scheme 15). Employing modified Robinson-Gabriel conditions developed by Wipf, ${ }^{86}$ oxazole $\mathbf{8 5}$ was formed cleanly. Subsequent stannylation afforded vinyl stannane 86, which was coupled with vinyl iodide 73 via a Stille cross-coupling ${ }^{63}$ to give the truncated monomer in anticipation for the key macrocyclisation step. At this stage, we discovered that a series of oxidation state adjustments and protecting group manipulations

400 were critical for the success of the macrocycle formation. While conditions required for methyl ester hydrolysis concomitantly unmasked the required $\mathrm{C} 18-\mathrm{OH}$, Yamaguchi macrolactonisation conditions ${ }^{39}$ disappointingly afforded a mixture of oligomers, primarily corresponding to the monomeric truncate. As such, we were forced to adopt a stepwise approach to access both coupling partners for the macrolactonisation. A controlled reduction

405 to the aldehyde $\mathbf{8 7}$ therefore was performed, meaning that this key intermediate could be subjected to either a controlled C18-OTMS desilylation (88) or a Pinnick oxidation to afford seco-acid 89. 


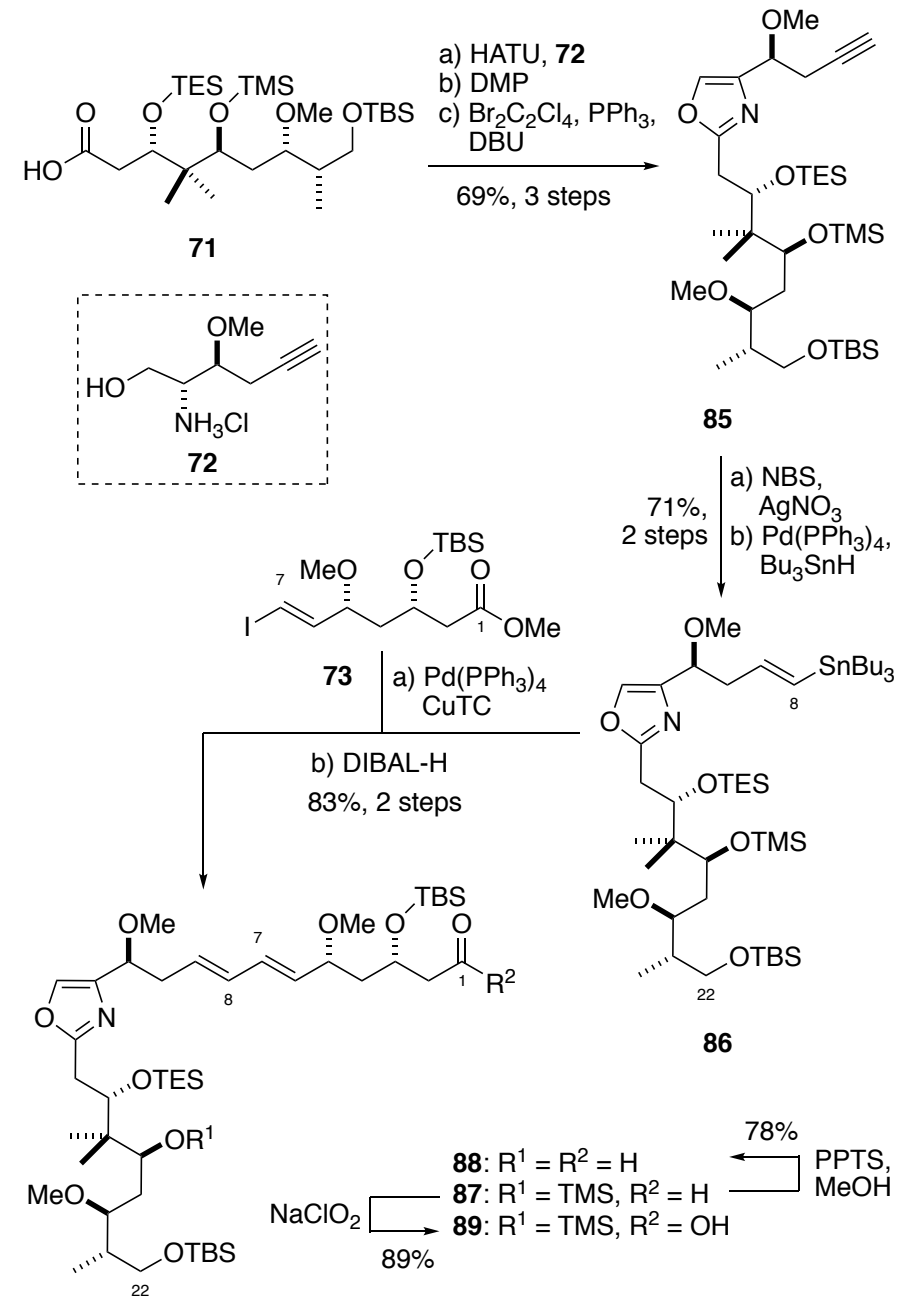

Scheme 15. Synthesis of the truncated C1-C22 monomers

Following these manoeuvres, a selective esterification between alcohol $\mathbf{8 8}$ and seco-acid 89 served to complete the linear carbon skeleton in 90 (Scheme 16). This was followed by a similar sequence of desilylation, oxidation and macrolactonisation to close the required macrocycle 91. The $C_{2}$-symmetry of the molecule presented the opportunity of performing a 415 bidirectional side-chain installation in the endgame. This required a selective C22-22' primary TBS ether cleavage, a capricious operation owing to the presence of multiple secondary silyl protecting groups of similar lability. In the end, carefully controlled exposure of the protected macrocycle 91 to HF/py selectively afforded the C22/22' diol 92 which, following oxidation, underwent a double boron-mediated aldol addition with ketone $\mathbf{7 0}^{78}$ Drawing from our 420 reidispongiolide synthesis, ${ }^{78}$ a sequence involving a controlled dehydration, ${ }^{87}$ followed by a 
conjugate reduction and global deprotection concluded our synthesis of rhizopodin (3) in 29 steps in $0.2 \%$ overall yield. ${ }^{77}$ The eventual success of this project required judicious finetuning of the protecting group strategy and redox steps, emphasising the need for perseverance based on a flexible synthesis plan.

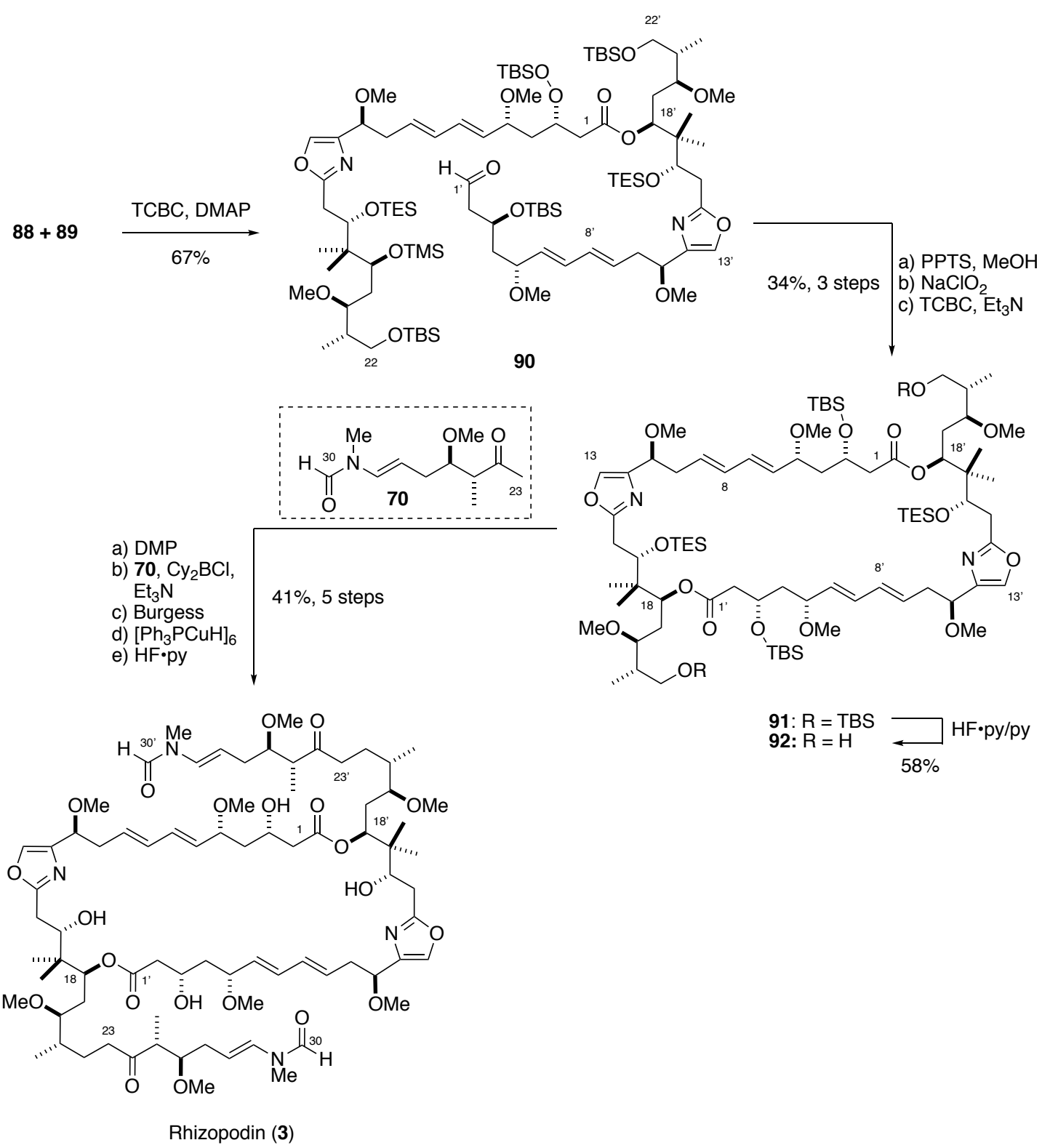

Scheme 16. Fragment union and completion of the total synthesis of rhizopodin (3) 


\section{Chivosazole F}

Following their discovery of rhizopodin, Höfle and Reichenbach reported the isolation of chivosazoles A-F from the myxobacterium Sorangium cellulosum in $1995 .{ }^{88,89}$ The chivosazoles are a structurally unprecedented class of polyene macrolides, with each member of the family differing in terms of the substitution at C11 and C20. Notably, the chivosazole family displayed potent inhibitory activity against filamentous fungi, yeast and a panel of

435 human cancer cell lines. This bioactivity stems from its selective inhibition of actin polymerisation. Intriguingly, the lack of structural homology to other known actin-binders suggests that the chivosazoles may have a distinct mode of action. ${ }^{90,91}$ What ignited our interest in the chivosazoles as a synthetic target was their astounding array of structural features (Scheme 17). Specifically, all congeners as typified by chivosazole F (4) possess a

440 31-membered macrolactone, containing 10 stereocentres and an oxazole moiety. However, the most impressive feature is the set of conjugated polyenes with alternating geometry in the macrocycle: a $(Z, E, Z, E)-\mathrm{C} 2-\mathrm{C} 9$ tetraene, a $(Z, E)-\mathrm{C} 12-\mathrm{C} 15$ diene and an $(E, E, Z)-\mathrm{C} 23-\mathrm{C} 28$ triene regions. ${ }^{92}$ These polyene regions demanded careful handling of sensitive late-stage intermediates and mild reaction conditions, necessary to suppress both potential olefin

445 isomerisation and degradation pathways. Perhaps as a reflection of the challenges imposed by this demanding target, only two total syntheses of chivosazole F (4), including our approach described below, have been reported to date. ${ }^{93,94}$

Our synthetic approach needed to address the delicate nature of the chivosazole structure; in particular, the isomerisation-prone $(2 Z, 4 E, 6 Z, 8 E)$-tetraene. Therefore, we sought

450 to minimise the number of endgame transformations. To this end, we envisaged a highly convergent approach towards accessing the full carbon skeleton by employing site-selective cross-couplings. This broadly disconnects the full carbon skeleton to reveal the C14-C35 northern hemisphere and the $\mathrm{C} 1-\mathrm{C} 13$ southern hemisphere of the natural product. 
The success of this strategy crucially relied on the judicious choice of coupling handles 455 and cross-coupling conditions. Building on initial intelligence gathering studies, we discovered that the Stille cross-coupling provided the most efficient means of fragment union. We also anticipated that a late-stage macrolactonisation might generate the macrocycle. This analysis revealed four constituent fragments - the C1-C5 fragment 93, the C6-C13 fragment 94, the C14-C26 fragment 95 and the C27-C 35 fragment 96.
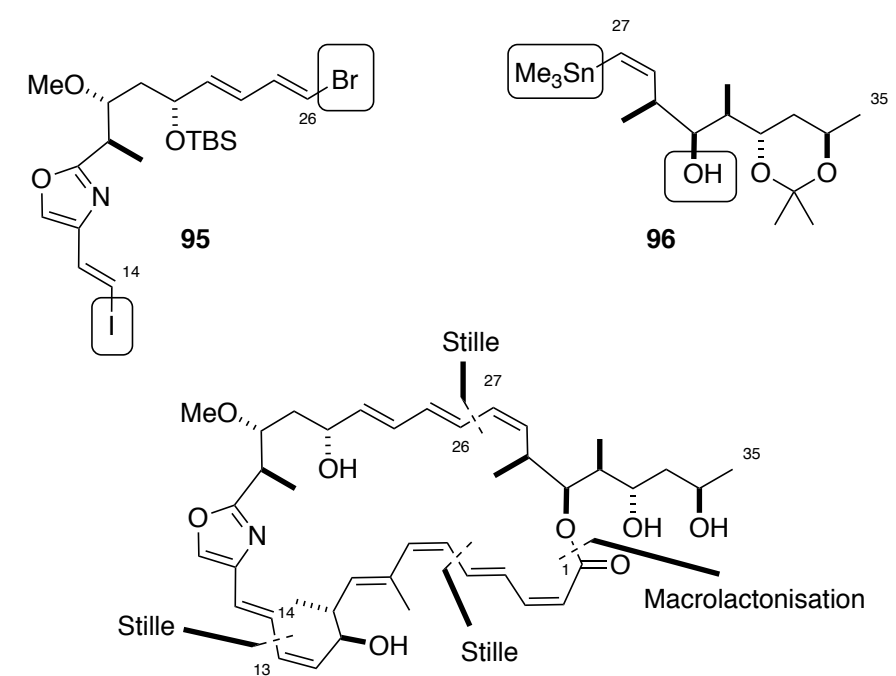

Chivosazole $\mathrm{F}(4)$

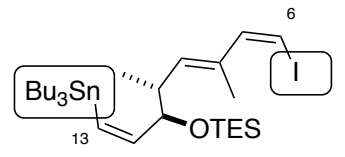

94

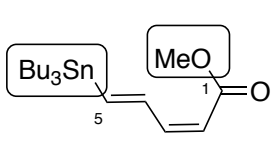

93

Scheme 17. Initial synthetic strategy towards chivosazole F (4) and the four proposed fragments

Recognising the 19,22-syn relationship, synthesis of the C14-C26 bis-halide linchpin commenced with an asymmetric boron-mediated aldol reaction from methyl ketone 97 and aldehyde $98^{95,96}$ to afford $\beta$-hydroxyketone 99 (Scheme 18A). This was then subjected to 465 Evans-Tishchenko reduction ${ }^{56}$ to establish the remaining stereocentre. The oxazoline ring was cyclised using $\mathrm{DAST}^{97}$ following amide formation from carboxylic acid $\mathbf{1 0 0}$ and amino alcohol 101. ${ }^{98}$ From oxazoline 102, oxazole formation using $\mathrm{MnO}_{2}$ proved incompatible with the pendant vinyl iodide functionality, suggesting that this oxidation step should be conducted post-fragment assembly. Beginning from the ethyl ketone derivative $\mathbf{1 0 3}$ of $(S)$-Roche ester 
and known aldehyde $\mathbf{1 0 4},{ }^{99,100}$ a boron-mediated aldol reaction ${ }^{101}$ readily installed the $\mathrm{C} 31$ and $\mathrm{C} 32$ stereocentres in $\beta$-hydroxyketone 105, with an Evans-Tishchenko reduction again employed to set the final C30 stereocentre (Scheme 18B). A six-step sequence revealed aldehyde 106, which was subjected to a Stork-Zhao olefination, deprotection and stannylation to afford the required stannane $96 .{ }^{49}$
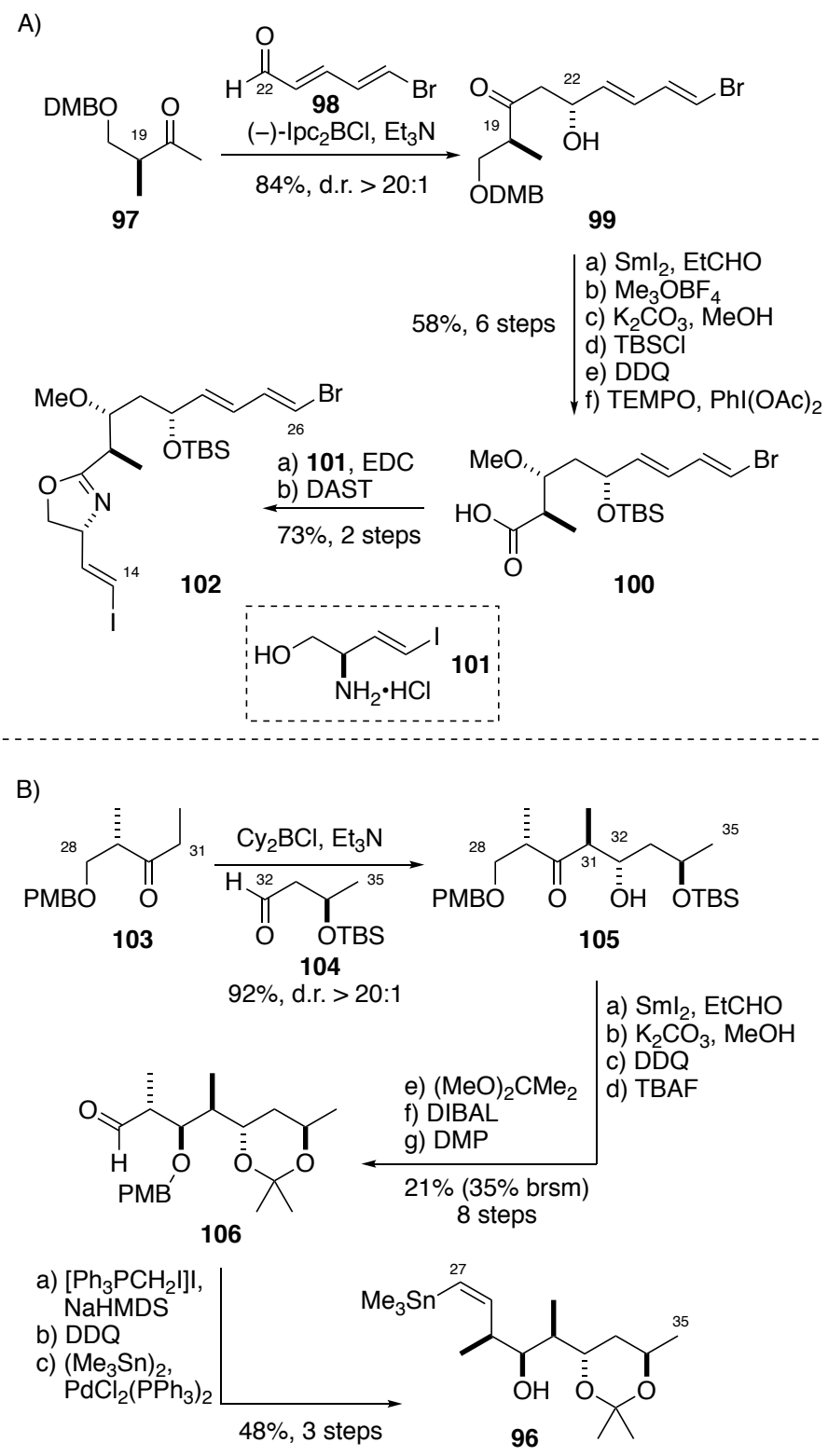

Scheme 18. A) Synthesis of the C14-C26 bis-halide linchpin 102. B) Synthesis of the C27-C35 vinyl stannane 96

The C1-C13 southern hemisphere contains what is arguably the most delicate polyene region of the chivosazoles. A vinylogous Mukaiyama aldol reaction ${ }^{102}$ between the chiral silyl 
480 ketene aminal 107 (derived from imide 108) with aldehyde 109 forged the two stereocentres in the C7-C13 fragment 110 (Scheme 19). ${ }^{103}$ Subsequent Stork-Zhao olefination of aldehyde 111 installed the terminal (6Z)-vinyl iodide in 112, which then engaged in a site-selective Stille cross-coupling with stannane $\mathbf{9 3}$ to afford the C1-C13 southern hemisphere $\mathbf{1 1 3}$ in preparation for exploring the planned fragment coupling sequence.

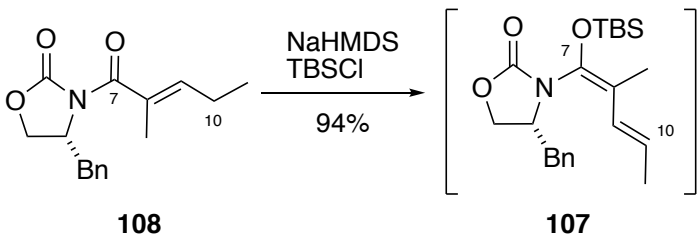

108

107
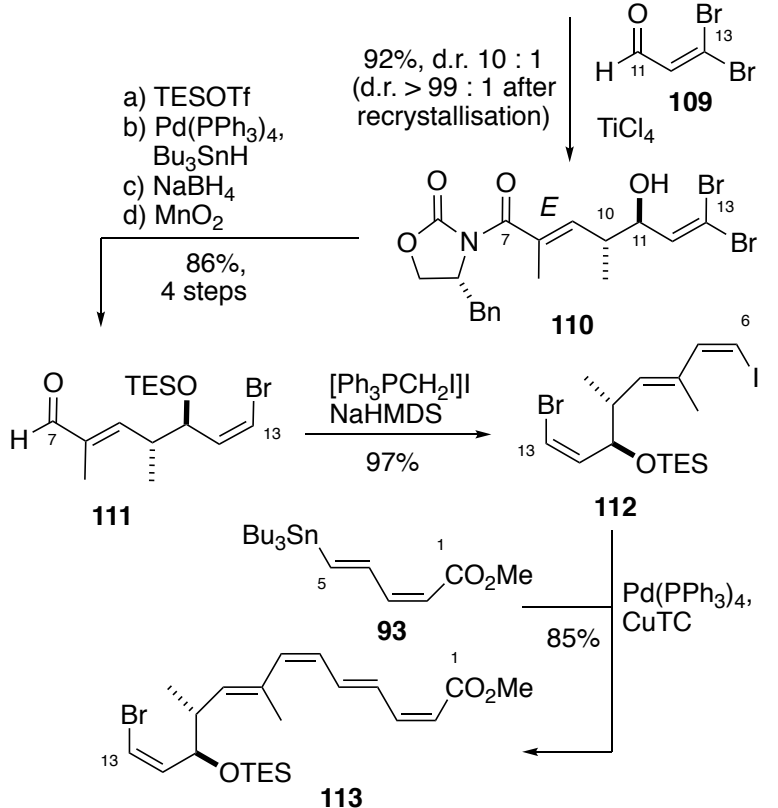

Scheme 19. Synthesis of the C1-C13 southern hemisphere fragment 113

With the two hemispheres in hand, we looked towards effecting the site-selective Stille coupling between the stannane 114 derived from 113 and bis-halide $\mathbf{1 0 2}$. Unfortunately, not only did this fail to effect the required coupling, it also highlighted the propensity for the tetraenoate 114 to isomerise under $\operatorname{Pd}(0)$ conditions (Scheme 20A). Similarly, model studies investigating the esterification of 115 with vinyl stannane 116, with the goal of effecting a macro-Stille ring closure, afforded the isomerised $(2 E, 4 E)$-stannane 117 under Yamaguchi 
495 conditions (Scheme 20B). To avoid handling the isomerisation-prone (2Z) olefin, we next investigated the possibility of achieving a late-stage macro-olefination with a pendant phosphonate ester at $\mathrm{C} 30$ in 118. The revised synthesis of the southern hemisphere thus involved a Stille coupling with vinyl iodide 94 and stannane 120 (Scheme 20C). 
A)
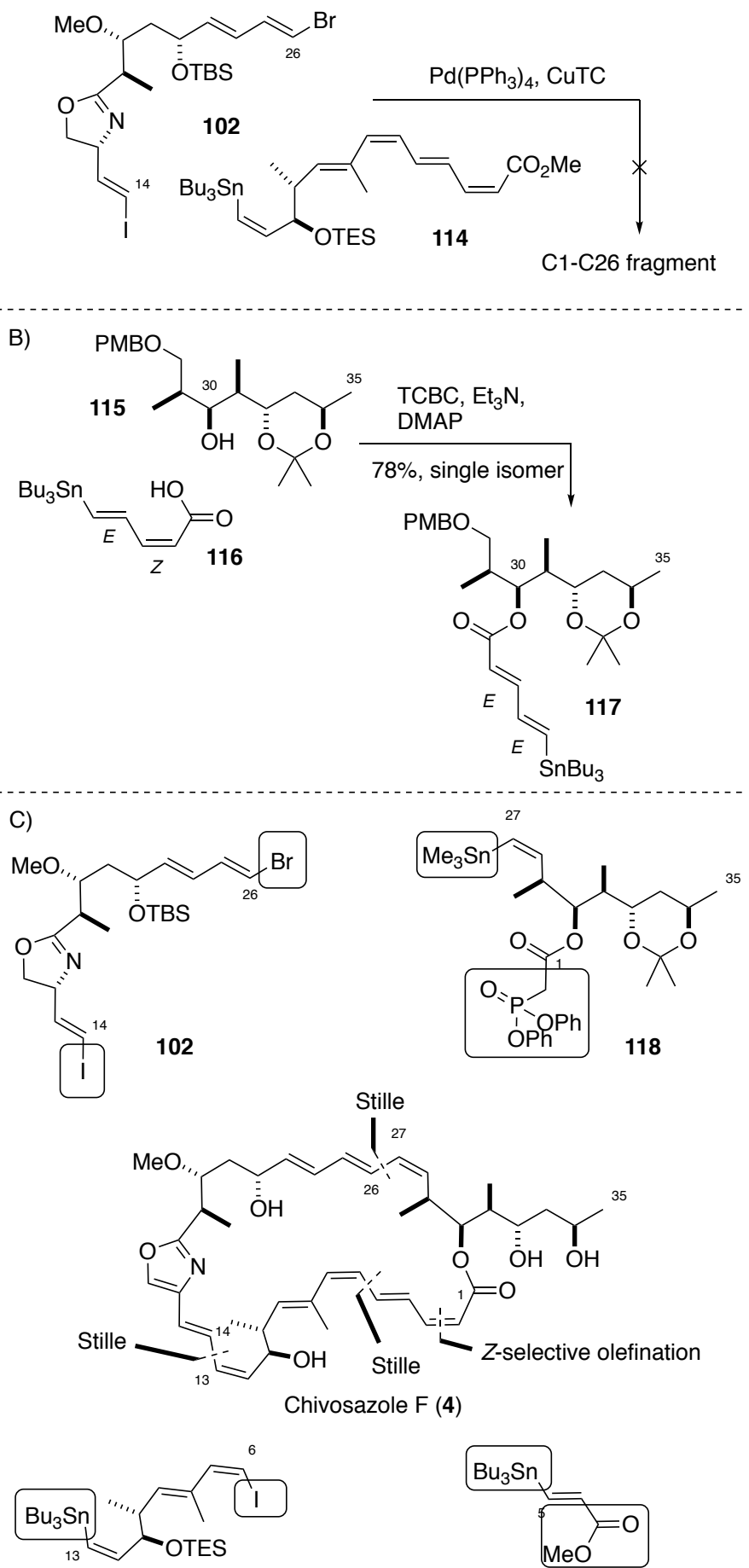

94

119

Scheme 20. A) Initial attempts at fragment union under Stille conditions failed to deliver the product and resulted in isomerisation of the tetraenoate. B) Esterification of alcohol 115 to the $\mathrm{C} 1-\mathrm{C} 5$ acid 116 resulted in concomitant isomerisation of the $\mathrm{C} 2$ olefin C) Our revised synthetic approach to chivosazole F (4)

Using optimised Stille cross-coupling conditions, and rationalising chemoselective coupling on steric and electronic grounds, we were able to append C3-C5 stannane 119 onto the C6-C13 vinyl iodide 94 to yield the C1-C13 tetraene 120 (Scheme 21). Crucially, addition 
of $t \mathrm{Bu}_{3} \mathrm{P}^{104}$ was required to prevent isomerisation of the $(6 Z)$-alkene. These conditions also allowed for the successful site-selective formation of the C13-C14 bond between bis-halide 102 and vinyl stannane 120, as well elaborating the resulting vinyl bromide 121 with the C27-

510 C35 fragment 118 (derived from vinyl iodide 122), with complete control of alkene geometry throughout the process. This success led us to ponder whether we could turn this into a onepot process. Remarkably, with sequential addition of each fragment (i. 119, ii. 94, iii. 102 and iv. 118), we were able to assemble the full carbon skeleton of the chivosazoles in $\mathbf{1 2 3}$ in one pot in $56 \%$ yield $(82 \%$ per coupling step). At this advanced stage, the $(4 E, 6 Z, 8 E)$-triene was

515 found to be highly prone to isomerisation on attempting to adjust the oxidation state at C3 ahead of the planned Horner-Wadsworth-Emmons (HWE) type macro-olefination. Furthermore, model studies on the planned Ando-olefination ${ }^{105}$ gave poor control over the desired $2 Z$ geometry. This series of disappointing and incredibly frustrating setbacks forced us to return to the drawing board... 


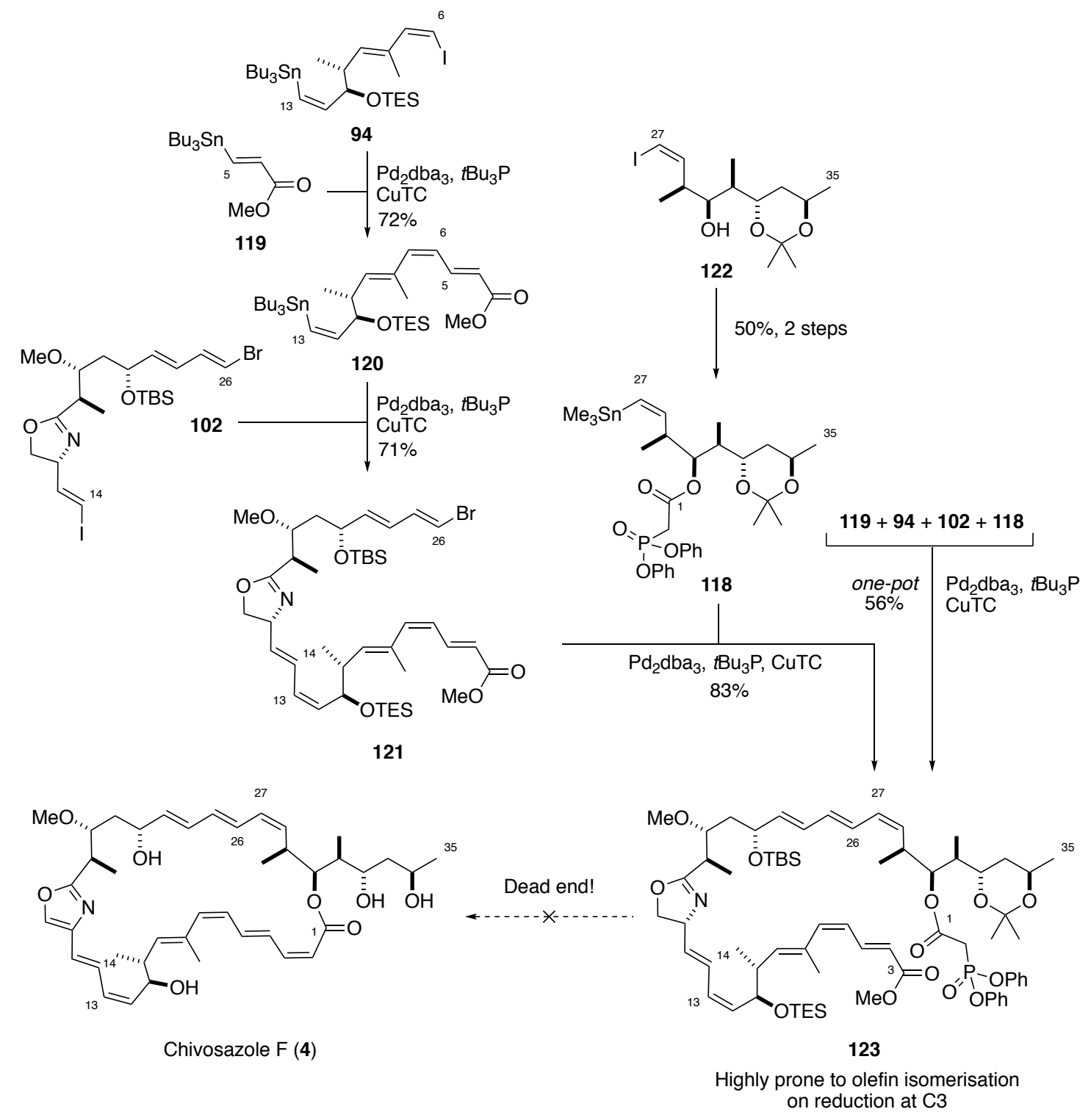

Scheme 21. Employing the site-selective Stille coupling strategy to form the chivosazole backbone

The challenges imposed by the delicate triene necessitated us to reconfigure our choreography of fragment coupling to an end-stage macro-Stille cyclisation (Scheme 22).

525 Furthermore, to access the (2Z) geometry, an alternative olefination strategy was required. The anticipated lability of the target molecule also prompted us to switch from an acetonide to a silylene protecting group for the 32,34-diol to facilitate a mild final deprotection. These alterations meant that our constituent fragments towards assembling 4 would involve a C3-C5 aldehyde 124, a revised C7-C13 stannane $\mathbf{1 2 5}$ and a revised C27-C35 phosphonate $\mathbf{1 2 6 .}$ 

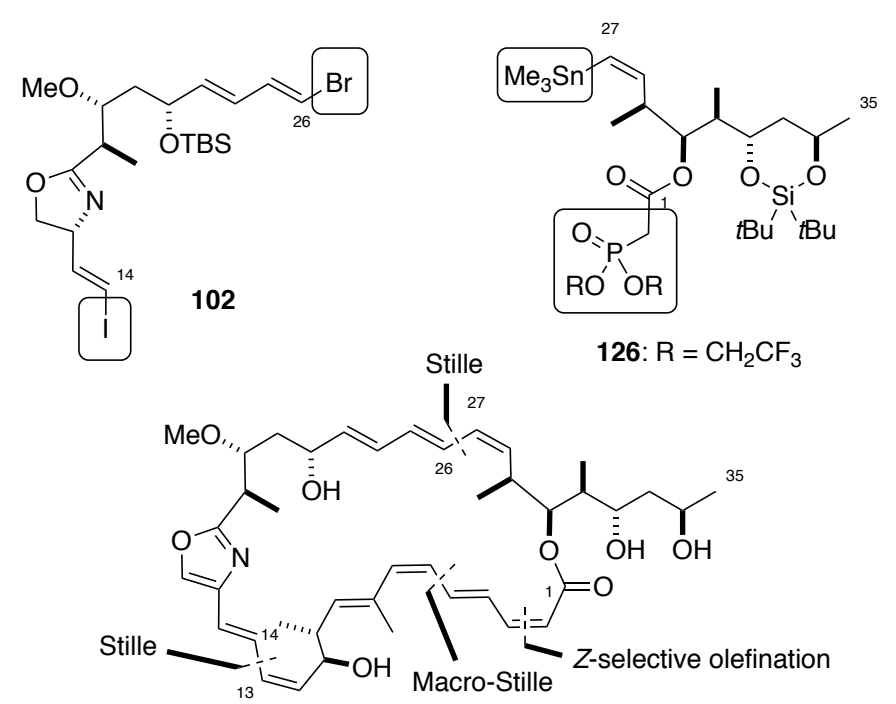

Chivosazole F (4)

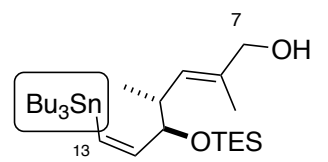

125

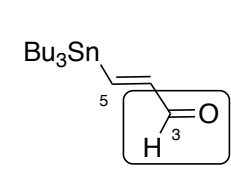

124

Scheme 22. Final strategy adopted towards the total synthesis of chivosazole F (4)

The revised C27-C35 phosphonate $\mathbf{1 2 6}$ was made from diol 127, ${ }^{94}$ an intermediate used in our previous routes. Building on the prior work, fragment coupling could be conducted in a stepwise manner (via the C7-C26 vinyl bromide 128) or a one-pot process (i. 102 ii. 125 iii. 126) to efficiently deliver the advanced fragment 129 (Scheme 23). Gratifyingly, employing the Still-Gennari type phosphonate afforded useful selectivities towards the desired $2 Z$ geometry for the HWE olefination with aldehyde $\mathbf{1 2 4} .^{106,107}$ At this stage, a double oxidation of the $\mathrm{C} 7-\mathrm{OH}$ and the oxazoline was carried out using $\mathrm{MnO}_{2}$, notably accomplishing the

540 challenging aromatisation on a delicate advanced fragment. Subsequently, the resulting aldehyde 130 was elaborated via a Stork-Zhao olefination to furnish the full carbon skeleton and also the seco precursor for the ring-closing intramolecular Stille reaction. To our delight, the critical macrocyclisation delivered the protected natural product with complete retention of olefin geometry. A final global deprotection concluded our total synthesis of chivosazole F (4) in 20 steps and $2.5 \%$ overall yield. Our success in this arduous campaign hinged upon 
careful initial analysis and planning, which fortunately, allowed for a highly convergent approach and a succinct endgame sequence. While we recognised the potential lability of such advanced polyene fragments, we could not have anticipated the frustration it brought. In this case, it truly stressed the importance of a flexible, modular strategy and the ability to adapt $550 \quad$ the strategy as required.

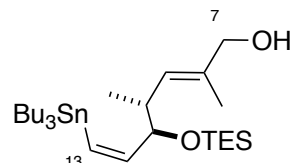

125
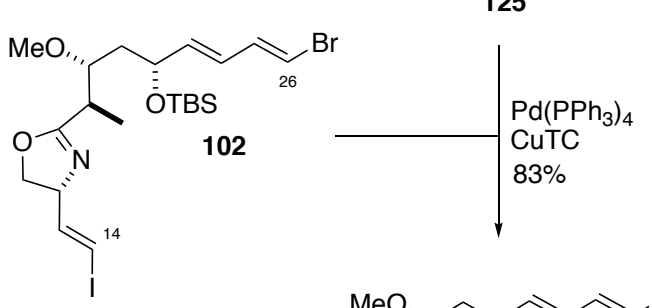<smiles>CCCOCC(C)C(O)C(C)CC(C)O</smiles>

127

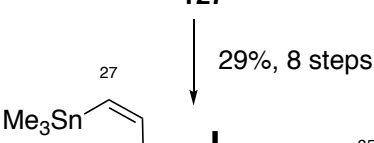

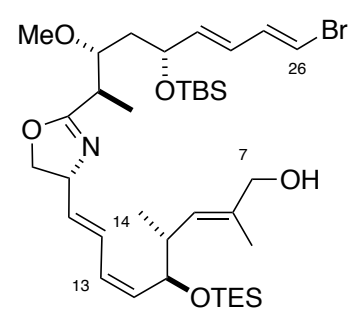

128<smiles>CCC[SbH2]C=CC=O</smiles>

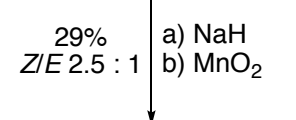<smiles>CC1C[C@H](C(C)C(OC=O)[C@H](C)/C=C\[Sb](C)(C)C)O[CH]O1</smiles>

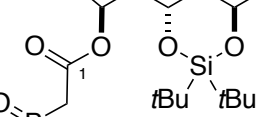

$\mathrm{O}_{\mathrm{F}}-\mathrm{OCH}_{\mathrm{OB}} \mathrm{ABu}^{\prime} \mathrm{tBu} \quad 102+125+126$

$\mathrm{OCH}_{2} \mathrm{CF}_{3} \quad 126$ \begin{tabular}{c|l}
$\begin{array}{c}\text { one-pot } \\
80 \%\end{array}$ & $\mathrm{Pd}\left(\mathrm{PPh}_{3}\right)$, \\
CuTC
\end{tabular}

$\mathrm{Pd}\left(\mathrm{PPh}_{3}\right)_{4}, \mathrm{CuTC}$ $88 \%$

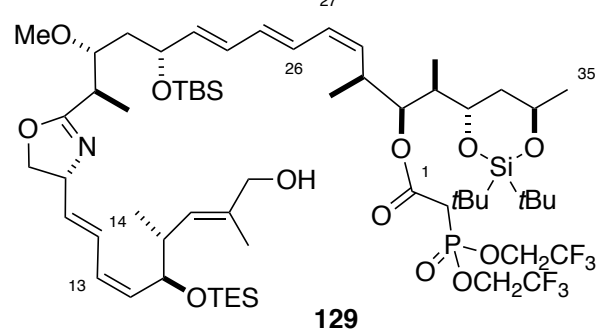

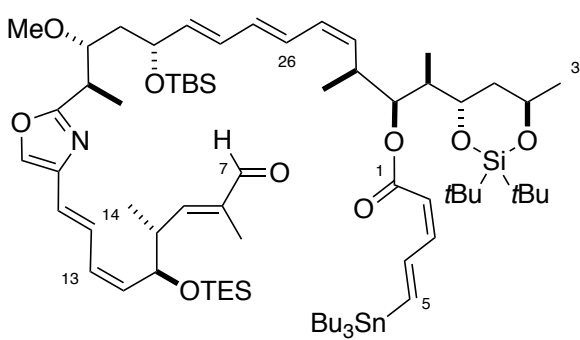

a) $\left[\mathrm{PPh}_{3} \mathrm{CH}_{2} \mathrm{I}\right] \mathrm{I}, \mathrm{NaHMDS}$

b) $\mathrm{Pd}\left(\mathrm{PPh}_{3}\right)_{4}, \mathrm{CuTC}$

c) HF•py

$41 \%, 3$ steps

130

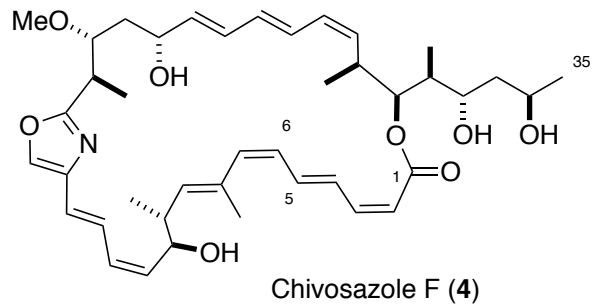

Scheme 23. Revised fragment coupling and completion of the total synthesis of chivosazole F (4) 


\section{Conclusions}

Our recent synthetic endeavours towards these highly challenging classes of complex polyketides not only showcases the versatility of our group's aldol methodology, but also highlights the trials and tribulations we overcame in a sustained campaign to achieve these enticing targets. In our total synthesis of spirastrellolide A methyl ester, we discovered that the subtle, unexpected structural effects imposed by distal protecting groups proved to be highly

560 consequential in the critical macrolactonisation. Similarly, for rhizopodin, a carefully choreographed sequence of protecting group incorporation and selective deprotection, was pivotal to achieving the target. Our campaign towards leiodermatolide underlines the need to reassess fragment coupling strategies when required. This is a common theme and important lesson - and was certainly a defining obstacle in our campaign towards chivosazole F. In the

565 end, a carefully orchestrated sequence of fragment coupling steps proved to be vital for success.

In this account, the highlighted setbacks and accompanying explanations of strategy evolution serve to illuminate the unanticipated difficulties that can make or break a total synthesis. Overall, we are provided with a humbling reminder that despite continual advances in the field of chemical synthesis, there is still much to be learned from tackling a structurally

570 complex natural product.

\section{Acknowledgements}

The work summarised in this review was carried out by generations of highly able students and postdocs at Cambridge, whose dedication, hard work and contributions are 575 gratefully acknowledged. We thank the Woolf Fisher Trust (scholarship to N.Y.S.L.) for support, Dr. Alison Findlay for helpful discussions and a thorough review of the manuscript, and the EPSRC UK National Mass Spectrometry Facility at Swansea University. 


\section{References}

580 1. Newman, D. J. \& Cragg, G. M. Marine natural products and related compounds in clinical and advanced preclinical trials. J. Nat. Prod. 67, 1216-1238 (2004).

2. Norcross, R. D. \& Paterson, I. Total synthesis of bioactive marine macrolides. Chem. Rev. 95, 2041-2114 (1995).

3. Newman, D. J. \& Cragg, G. M. Natural products as sources of new drugs from 1981 to 2014. J. Nat. Prod. 79, 629-661 (2016).

4. Yeung, K.-S. \& Paterson, I. Advances in the total synthesis of biologically important marine macrolides. Chem. Rev. 105, 4237-4313 (2005).

5. Paterson, I. \& Anderson, E. The Renaissance of Natural Products as Drug Candidates. Science 310, 451-453 (2005).

590 6. Dalby, S. M. \& Paterson, I. Synthesis of polyketide natural products and analogs as promising anticancer agents. Curr. Opin. Drug Discov. Devel. 13, 777-794 (2010).

7. Paterson, I. \& Findlay, A. D. Recent advances in the total synthesis of polyketide natural products as promising anticancer agents. Aust. J. Chem. 62, 624-638 (2009).

8. Kan, S. B. J., Ng, K. K.-H. \& Paterson, I. The impact of the Mukaiyama aldol reaction in total synthesis. Angew. Chem. Int. Ed. 52, 9097-9108 (2013).

9. Paterson, I. New methods and strategies for the stereocontrolled synthesis of polypropionate- derived natural products. Pure Appl. Chem. 64, 1821-1830 (1992).

10. Williams, D. E., Roberge, M., Van Soest, R. \& Andersen, R. J. Spirastrellolide A, an antimitotic macrolide isolated from the Caribbean marine sponge Spirastrella coccinea. J. Am. Chem. Soc. 125, 5296-5297 (2003).

11. Paterson, I., Maltas, P. \& Anderson, E. A. Total synthesis of (+)-spirastrellolide A methyl ester: Challenges and discoveries. Pure Appl. Chem. 85, 1133-1147 (2013).

12. Williams, D. E., Lapawa, M., Feng, X., Tarling, T., Roberge, M. \& Andersen, R. J. 
Spirastrellolide A: Revised structure, progress toward the relative configuration, and inhibition of protein phosphatase 2A. Org. Lett. 6, 2607-2610 (2004).

13. Warabi, K., Williams, D. E., Patrick, B. O., Roberge, M. \& Andersen, R. J. Spirastrellolide B reveals the absolute configuration of the spirastrellolide macrolide core. J. Am. Chem. Soc. 129, 508-509 (2007).

14. Williams, D. E., Keyzers, R. A., Warabi, K., Desjardine, K., Riffell, J. L., Roberge, M. \& Andersen, R. J. Spirastrellolides C to G: Macrolides obtained from the marine sponge Spirastrella coccinea. J. Org. Chem. 72, 9842-9845 (2007).

15. Paterson, I. \& Dalby, S. M. Synthesis and stereochemical determination of the spirastrellolides. Nat. Prod. Rep. 26, 865-873 (2009).

16. Vintonyak, V. V, Antonchick, A. P., Rauh, D. \& Waldmann, H. The therapeutic potential of phosphatase inhibitors. Curr. Opin. Chem. Biol. 13, 272-283 (2009).

17. O’Neil, G. W., Ceccon, J., Benson, S., Collin, M.-P., Fasching, B. \& Fürstner, A. Total synthesis of spirastrellolide F methyl ester - part 1: Strategic considerations and revised approach to the southern hemisphere. Angew. Chem. Int. Ed. 48, 99409945 (2009).

620 18. Benson, S., Collin, M.-P., O’Neil, G. W., Ceccon, J., Fasching, B., Fenster, M. D. B., Godbout, C., Radkowski, K., Goddard, R. \& Fürstner, A. Total synthesis of spirastrellolide F methyl ester - part 2: Macrocyclization and completion of the synthesis. Angew. Chem. Int. Ed. 48, 9946-9950 (2009).

19. Benson, S., Collin, M.-P., Arlt, A., Gabor, B., Goddard, R. \& Fürstner, A. Secondgeneration total synthesis of spirastrellolide $\mathrm{F}$ methyl ester: The alkyne route. Angew. Chem. Int. Ed. 50, 8739-8744 (2011).

20. Arlt, A., Benson, S., Schulthoff, S., Gabor, B. \& Fürstner, A. A total synthesis of spirastrellolide A methyl ester. Chem. Eur. J. 19, 3596-3608 (2013). 
21. Paterson, I., Anderson, E. A., Dalby, S. M., Lim, J. H., Genovino, J., Maltas, P. \& Moessner, C. Total synthesis of spirastrellolide A methyl ester-Part 1: Synthesis of an advanced C17-C40 bis-spiroacetal Subunit. Angew. Chem. Int. Ed. 47, 30163020 (2008).

22. Paterson, I., Anderson, E. A., Dalby, S. M., Lim, J. H., Genovino, J., Maltas, P. \& Moessner, C. Total synthesis of spirastrellolide A methyl ester-Part 2: Subunit union and completion of the synthesis. Angew. Chem. Int. Ed. 47, 3021-3025 (2008).

23. Paterson, I., Maltas, P., Dalby, S. M., Lim, J. H. \& Anderson, E. A. A secondgeneration total synthesis of spirastrellolide A methyl ester. Angew. Chem. Int. Ed. 51, 2749-2753 (2012).

640 24. Paterson, I., Anderson, E. A., Dalby, S. M., Lim, J. H., Maltas, P., Loiseleur, O., Genovino, J. \& Moessner, C. The stereocontrolled total synthesis of spirastrellolide A methyl ester. Expedient construction of the key fragments. Org. Biomol. Chem. 10, 5861-5872 (2012).

25. Paterson, I., Anderson, E. A., Dalby, S. M., Lim, J. H., Loiseleur, O., Maltas, P. \& Moessner, C. Progress toward a total synthesis of spirastrellolide A. Pure Appl. Chem. 79, 667-676 (2007).

26. Paterson, I., Anderson, E. A., Dalby, S. M., Lim, J. H. \& Maltas, P. The stereocontrolled total synthesis of spirastrellolide A methyl ester. Fragment coupling studies and completion of the synthesis. Org. Biomol. Chem. 10, 58735886 (2012).

27. Chatterjee, A. K., Choi, T.-L., Sanders, D. P. \& Grubbs, R. H. A general model for selectivity in olefin cross metathesis. J. Am. Chem. Soc. 125, 11360-11370 (2003).

28. Nicolaou, K. C., Bulger, P. G. \& Sarlah, D. Metathesis reactions in total synthesis. 
Angew. Chem. Int. Ed. 44, 4490-4527 (2005).

655 29. Miyaura, N. \& Suzuki, A. Palladium-catalyzed cross-coupling reactions of organoboron compounds. Chem. Rev. 95, 2457-2483 (1995).

30. Paterson, I., Anderson, E. A., Dalby, S. M., Lim, J. H., Maltas, P. \& Moessner, C. Synthesis of the DEF-bis-spiroacetal of spirastrellolide A exploiting a double asymmetric dihydroxylation/spiroacetalisation strategy. Chem. Commun. 4186660 4188 (2006).

31. Paterson, I., Anderson, E. A., Dalby, S. M. \& Loiseleur, O. Toward the synthesis of spirastrellolide A: Construction of a tetracyclic C26-C40 subunit containing the DEF-bis-spiroacetal. Org. Lett. 7, 4121-4124 (2005).

32. Shaojing, H., Jayaraman, S. \& Oehlschlager, A. C. Diastereo- and enantioselective 665 synthesis of syn- $\alpha$-vinylchlorohydrins and cis-vinylepoxides. J. Org. Chem. 61, 7513-7520 (1996).

33. Paterson, I., Wallace, D. J. \& Cowden, C. J. Polyketide synthesis using the boronmediated, anti-aldol reactions of lactate-derived ketones: Total synthesis of (-)ACRL toxin IIIB. Synthesis 1998, 639-652 (1998).

670 34. Kolb, H. C., VanNieuwenhze, M. S. \& Sharpless, K. B. Catalytic asymmetric dihydroxylation. Chem. Rev. 94, 2483-2547 (1994).

35. Paterson, I., Anderson, E. A., Dalby, S. M. \& Loiseleur, O. Toward the synthesis of spirastrellolide A: Construction of two $\mathrm{C} 1-\mathrm{C} 25$ diastereomers containing the $\mathrm{BC}$ spiroacetal. Org. Lett. 7, 4125-4128 (2005).

675 36. Chemler, S. R., Trauner, D. \& Danishefsky, S. J. The B-alkyl Suzuki-Miyaura cross-coupling reaction: Development, mechanistic study, and applications in natural product synthesis. Angew. Chem. Int. Ed. 40, 4544-4568 (2001).

37. Takai, K., Kimura, K., Kuroda, T., Hiyama, T. \& Nozaki, H. Selective Grignard- 
type carbonyl addition of alkenyl halides mediated by chromium(II) chloride. Tetrahedron Lett. 24, 5281-5284 (1983).

38. Jin, H., Uenishi, J., Christ, W. J. \& Kishi, Y. Catalytic effect of nickel(II) chloride and palladium(II) acetate on chromium(II)-mediated coupling reaction of iodo olefins with aldehydes. J. Am. Chem. Soc. 108, 5644-5646 (1986).

39. Inanaga, J., Hirata, K., Saeki, H., Katsuki, T. \& Yamaguchi, M. A rapid esterification by means of mixed anhydride and its application to large-ring lactonization. Bull. Chem. Soc. Jpn. 52, 1989-1993 (1979).

40. Shiina, I., Kubota, M., Oshiumi, H. \& Hashizume, M. An effective use of benzoic anhydride and its derivatives for the synthesis of carboxylic esters and lactones: A powerful and convenient mixed anhydride method promoted by basic catalysts. $J$. Org. Chem. 69, 1822-1830 (2004).

41. Wright, A. E., Reed, J. K., Roberts, J. \& Longley, R. E. Antiproliferative activity of the leiodermatolide class of macrolides. U.S. Pat. Appl. Publ. (USA), US2008033035.

42. Paterson, I., Dalby, S. M., Roberts, J. C., Naylor, G. J., Guzmán, E. A., Isbrucker, R., Pitts, T. P., Linley, P., Divlianska, D., Reed, J. K., et al. Leiodermatolide, a potent antimitotic macrolide from the marine sponge Leiodermatium sp. Angew. Chem. Int. Ed. 50, 3219-3223 (2011).

43. Smith, S. G. \& Goodman, J. M. Assigning stereochemistry to single diastereoisomers by GIAO NMR calculation: The DP4 probability. J. Am. Chem. Soc. 132, 12946-12959 (2010).

44. Reiss, A. \& Maier, M. E. Toward leiodermatolide: Synthesis of the core structure. Org. Lett. 18, 3146-3149 (2016).

45. Rink, C., Navickas, V. \& Maier, M. E. An approach to the core structure of 
leiodermatolide. Org. Lett. 13, 2334-2337 (2011).

46. Mailhol, D., Willwacher, J., Kausch-Busies, N., Rubitski, E. E., Sobol, Z., Schuler, M., Lam, M.-H., Musto, S., Loganzo, F., Maderna, A., et al. Synthesis, molecular editing, and biological assessment of the potent cytotoxin leiodermatolide. J. Am. Chem. Soc. 136, 15719-15729 (2014).

47. Willwacher, J., Kausch-Busies, N. \& Fürstner, A. Divergent total synthesis of the antimitotic agent leiodermatolide. Angew. Chem. Int. Ed. 51, 12041-12046 (2012).

48. Paterson, I., Paquet, T. \& Dalby, S. M. Synthesis of the macrocyclic core of leiodermatolide. Org. Lett. 13, 4398-4401 (2011).

49. Wulff, W. D., Peterson, G. A., Bauta, W. E., Chan, K.-S., Faron, K. L., Gilbertson, S. R., Kaesler, R. W., Yang, D. C. \& Murray, C. K. A regioselective entry to vinyl lithiums from unsymmetrical ketones via enol triflates. J. Org. Chem. 51, 277-279 (1986).

50. Kočovský, P. Carbamates : A method of synthesis and some synthetic applications. Tetrahedron Lett. 27, 5521-5524 (1986).

51. Paterson, I. \& Williams, S. Strategy evolution in the total synthesis of (-)leiodermatolide. Isr. J. Chem. 57, 192-201 (2017).

52. Comins, D. L. \& Dehghani, A. Pyridine-derived triflating reagents: An improved preparation of vinyl triflates from metallo enolates. Tetrahedron Lett. 33, 62996302 (1992).

53. Gray, M., Andrews, I. P., Hook, D. F., Kitteringham, J. \& Voyle, M. Practical methylation of aryl halides by Suzuki-Miyaura coupling. Tetrahedron Lett. 41, $6237-6240$ (2000).

54. Paterson, I., Wallace, D. J. \& Velázquez, S. M. Studies in polypropionate synthesis: High $\pi$-face selectivity in syn and anti aldol reactions of chiral boron enolates of 
lactate-derived ketones. Tetrahedron Lett. 35, 9083-9086 (1994).

730 55. Paterson, I. \& Wallace, D. J. Manipulation of the aldol adducts from lactate-derived ketones. A versatile chiral auxiliary for the asymmetric synthesis of $\beta$-hydroxy carbonyl compounds. Tetrahedron Lett. 35, 9087-9090 (1994).

56. Evans, D. A. \& Hoveyda, A. H. Samarium-catalyzed intramolecular Tishchenko reduction of $\beta$-hydroxy ketones. A stereoselective approach to the synthesis of differentiated anti 1,3-diol monoesters. J. Am. Chem. Soc. 112, 6447-6449 (1990).

57. Evans, D. A., Chapman, K. T. \& Carreira, E. M. Directed reduction of $\beta$-hydroxy ketones employing tetramethylammonium triacetoxyborohydride. J. Am. Chem. Soc. 110, 3560-3578 (1988).

58. Taniguchi, M., Kobayashi, S., Nakagawa, M., Hino, T. \& Kishi, Y. $\beta$-Halovinyl ketones: Synthesis from acetylenic ketones. Tetrahedron Lett. 27, 4763-4766 (1986).

59. Paterson, I., Ng, K. K.-H., Williams, S., Millican, D. C. \& Dalby, S. M. Total synthesis of the antimitotic marine macrolide (-)-leiodermatolide. Angew. Chem. Int. Ed. 53, 2692-2695 (2014).

745 60. Mukaiyama, T., Banno, K. \& Narasaka, K. New cross-aldol reactions. Reactions of silyl enol ethers with carbonyl compounds activated by titanium tetrachloride. $J$. Am. Chem. Soc. 96, 7503-7509 (1974).

61. Evans, D. A., Dart, M. J., Duffy, J. L., Yang, M. G. \& Livingston, A. B. Diastereoselective aldol and allylstannane addition reactions. The merged stereochemical impact of $\alpha$ and $\beta$ aldehyde substituents. J. Am. Chem. Soc. 117, 6619-6620 (1995).

62. Jeffery, T., Ui, T., Plattner, R. D., Yokoyama, T., Uyehara, T., Namai, T., Yamanaka, S., Harada, N., Nakano, F. \& Matsuzaki, A. Palladium-catalysed 
reaction of vinylic halides with allylic alcohols: a highly chemo-, regio- and stereocontrolled synthesis of conjugated dienols. J. Chem. Soc. Chem. Commun. 324-325 (1991).

63. Fürstner, A., Funel, J.-A., Tremblay, M., Bouchez, L. C., Nevado, C., Waser, M., Ackerstaff, J. \& Stimson, C. C. A versatile protocol for Stille-Migita cross coupling reactions. Chem. Commun. 2873-2875 (2008).

760 64. Stille, J. K. \& Groh, B. L. Stereospecific cross-coupling of vinyl halides with vinyl tin reagents catalyzed by palladium. J. Am. Chem. Soc. 109, 813-817 (1987).

65. Guzmán, E. A., Xu, Q., Pitts, T. P., Mitsuhashi, K. O., Baker, C., Linley, P. A., Oestreicher, J., Tendyke, K., Winder, P. L., Suh, E. M., et al. Leiodermatolide, a novel marine natural product, has potent cytotoxic and antimitotic activity against cancer cells, appears to affect microtubule dynamics, and exhibits antitumor activity. Int. J. Cancer 139, 2116-2126 (2016).

66. Sasse, F., Steinmetz, H., Höfle, G. \& Reichenbach, H. Rhizopodin, a new compound from Myxococcus stipitatus (myxobacteria) causes formation of rhizopodia-like structures in animal cell cultures. Production, isolation, physicochemical and biological properties. J. Antibiot. (Tokyo). 46, 741-748 (1993).

67. Gronewold, T. M. A., Sasse, F., Lünsdorf, H. \& Reichenbach, H. Effects of rhizopodin and latrunculin B on the morphology and on the actin cytoskeleton of mammalian cells. Cell Tissue Res. 295, 121-129 (1999).

68. Jansen, R., Steinmetz, H., Sasse, F., Schubert, W.-D., Hagelüken, G., Albrecht, S. C. \& Müller, R. Isolation and structure revision of the actin-binding macrolide rhizopodin from Myxococcus stipitatus (Myxobacteria). Tetrahedron Lett. 49, 5796-5799 (2008).

69. Horstmann, N. \& Menche, D. Configurational assignment of rhizopodin, an actin- 
binding macrolide from the myxobacterium Myxococcus stipitatus. Chem. Commun. 5173-5175 (2008).

70. Pulukuri, K. K. \& Chakraborty, T. K. Stereoselective synthesis of the monomeric unit of actin binding macrolide rhizopodin. Org. Lett. 14, 2858-2861 (2012).

71. Chen, Z., Song, L., Xu, Z. \& Ye, T. Synthesis of the C9-C23 (C9'-C23') fragment of the dimeric natural product rhizopodin. Org. Lett. 12, 2036-2039 (2010).

785 72. Nicolaou, K. C., Jiang, X., Lindsay-Scott, P. J., Corbu, A., Yamashiro, S., Bacconi, A. \& Fowler, V. M. Total synthesis and biological evaluation of monorhizopodin and 16-epi-monorhizopodin. Angew. Chem. Int. Ed. 50, 1139-1144 (2011).

73. Pulukuri, K. K. \& Chakraborty, T. K. Formal synthesis of actin binding macrolide rhizopodin. Org. Lett. 16, 2284-2287 (2014).

790 74. Bender, T., Loits, D., White, J. M. \& Rizzacasa, M. A. Synthesis of the C1-C18 fragment of rhizopodin: Late-state introduction of the oxazole. Org. Lett. 16, 14501453 (2014).

75. Dieckmann, M., Kretschmer, M., Li, P., Rudolph, S., Herkommer, D. \& Menche, D. Total synthesis of rhizopodin. Angew. Chem. Int. Ed. 51, 5667-5670 (2012).

795 76. Kretschmer, M., Dieckmann, M., Li, P., Rudolph, S., Herkommer, D., Troendlin, J. \& Menche, D. Modular total synthesis of rhizopodin: A highly potent G-actin dimerizing macrolide. Chem. Eur. J. 19, 15993-16018 (2013).

77. Dalby, S. M., Goodwin-Tindall, J. \& Paterson, I. Total synthesis of (-)-rhizopodin. Angew. Chem. Int. Ed. 52, 6517-6521 (2013).

800 78. Paterson, I., Ashton, K., Britton, R., Cecere, G., Chouraqui, G., Florence, G. J., Knust, H. \& Stafford, J. Total synthesis of (-)-reidispongiolide A, an actin-targeting macrolide isolated from the marine sponge Reidispongia coerulea. Chem. Asian J. 3, 367-387 (2008). 
79. Jadhav, P. K., Bhat, K. S., Perumal, P. T. \& Brown, H. C. Chiral synthesis via organoboranes. 6. Asymmetric allylboration via chiral allyldialkylboranes. Synthesis of homoallylic alcohols with exceptionally high enantiomeric excess. $J$. Org. Chem. 51, 432-439 (1986).

80. Hinterding, K., Singhanat, S. \& Oberer, L. Stereoselective synthesis of polyketide fragments using a novel intramolecular Claisen-like condensation/reduction sequence. Tetrahedron Lett. 42, 8463-8465 (2001).

81. Hanson, R. M. \& Sharpless, K. B. Procedure for the catalytic asymmetric epoxidation of allylic alcohols in the presence of molecular sieves. J. Org. Chem. 51, 1922-1925 (1986).

82. Gao, Y., Klunder, J. M., Hanson, R. M., Masamune, H., Ko, S. Y. \& Sharpless, K. B. Catalytic asymmetric epoxidation and kinetic resolution: modified procedures including in situ derivatization. J. Am. Chem. Soc. 109, 5765-5780 (1987).

83. De Rosa, M., Soriente, A. \& Scettri, A. Enantioselective aldol condensation of Osilyl dienolates to aldehydes mediated by chiral BINOL-titanium complexes. Tetrahedron: Asymmetry 11, 3187-3195 (2000).

820 84. Paterson, I., Davies, R. D. M., Heimann, A. C., Marquez, R. \& Meyer, A. Stereocontrolled total synthesis of (-)-callipeltoside A. Org. Lett. 5, 4477-4480 (2003).

85. Narasaka, K. \& Pai, F.-C. Stereoselective reduction of $\beta$ hydroxyketones to 1,3diols highly selective 1,3-asymmetric induction via boron chelates. Tetrahedron $\mathbf{4 0 ,}$ 2233-2238 (1984).

86. Wipf, P. \& Graham, T. H. Synthesis of the C1'-C11' segment of leucascandrolide A. J. Org. Chem. 66, 3242-3245 (2001).

87. Burgess, E. M., Penton, H. R. \& Taylor, E. A. Thermal reactions of alkyl N- 
carbomethoxysulfamate esters. J. Org. Chem. 38, 26-31 (1973).

830 88. Irschik, H., Jansen, R., Gerth, K., Höfle, G. \& Reichenbach, H. Chivosazole A, a new inhibitor of eukaryotic organisms isolated from myxobacteria. J. Antibiot. (Tokyo). 48, 962-966 (1995).

89. Jansen, R., Irschik, H., Reichenbach, H. \& Höfle, G. Chivosazoles A-F: Novel antifungal and cytotoxic macrolides from Sorangium cellulosum (Myxobacteria). Liebigs Ann. 1997, 1725-1732 (1997).

90. Diestel, R., Irschik, H., Jansen, R., Khalil, M. W., Reichenbach, H. \& Sasse, F. Chivosazoles A and F, cytostatic macrolides from myxobacteria, interfere with actin. ChemBioChem 10, 2900-2903 (2009).

91. Yeung, K.-S. \& Paterson, I. Actin-binding marine macrolides: Total synthesis and biological importance. Angew. Chem. Int. Ed. 41, 4632-4653 (2002).

92. Janssen, D., Albert, D., Jansen, R., Müller, R. \& Kalesse, M. Chivosazole A Elucidation of the absolute and relative configuration. Angew. Chem. Int. Ed. 46, 4898-4901 (2007).

93. Brodmann, T., Janssen, D. \& Kalesse, M. Total synthesis of chivosazole F. J. Am. Chem. Soc. 132, 13610-13611 (2010).

94. Williams, S., Jin, J., Kan, S. B. J., Li, M., Gibson, L. J. \& Paterson, I. An expedient total synthesis of chivosazole F: An actin-binding antimitotic macrolide from the myxobacterium Sorangium cellulosum. Angew. Chem. Int. Ed. 56, 645-649 (2017).

95. Paterson, I., Goodman, J. M., Anne Lister, M., Schumann, R. C., McClure, C. K. \& Norcross, R. D. Enantio- and diastereoselective aldol reactions of achiral ethyl and methyl ketones with aldehydes: the use of enol diisopinocampheylborinates. Tetrahedron 46, 4663-4684 (1990).

96. Paterson, I., Goodman, J. M. \& Isaka, M. Aldol reactions in polypropionate 
synthesis: High $\pi$-face selectivity of enol borinates from $\alpha$-chiral methyl and ethyl ketones under substrate control. Tetrahedron Lett. 30, 7121-7124 (1989).

97. Phillips, A. J., Uto, Y., Wipf, P., Reno, M. J. \& Williams, D. R. Synthesis of functionalized oxazolines and oxazoles with DAST and Deoxo-Fluor. Org. Lett. 2, $1165-1168$ (2000).

98. Campbell, A. D., Paterson, D. E., Taylor, R. J. K. \& Raynham, T. M. exo-Glycal 860 approaches to C-linked glycosyl amino acid synthesis. Chem. Commun. 1599-1600 (1999).

99. Kitamura, M., Tokunaga, M., Ohkuma, T. \& Noyori, R. Convenient preparation of BINAP-ruthenium(II) complexes catalyzing asymmetric hydrogenation of functionalized ketones. Tetrahedron Lett. 32, 4163-4166 (1991).

865 100. Duplantier, A. J. \& Masamune, S. Pimaricin. Stereochemistry and synthesis of its aglycon (pimarolide) methyl ester. J. Am. Chem. Soc. 112, 7079-7081 (1990).

101. Paterson, I., Gibson, L. J. \& Kan, S. B. J. Synthesis of the C15-C35 northern hemisphere subunit of the chivosazoles. Org. Lett. 12, 5530-5533 (2010).

102. Shirokawa, S. I., Kamiyama, M., Nakamura, T., Okada, M., Nakazaki, A., Hosokawa, S. \& Kobayashi, S. Remote asymmetric induction with vinylketene silyl N,O-acetal. J. Am. Chem. Soc. 126, 13604-13605 (2004).

103. Paterson, I., Kan, S. B. J. \& Gibson, L. J. Synthesis of the C1-C13 tetraenoate subunit of the chivosazoles. Org. Lett. 12, 3724-3727 (2010).

104. Littke, A. F., Schwarz, L. \& Fu, G. C. Pd/P(t-Bu)3: A mild and general catalyst for Stille reactions of aryl chlorides and aryl bromides. J. Am. Chem. Soc. 124, 63436348 (2002).

105. Ando, K. Highly selective synthesis of Z-unsaturated esters by using new HornerEmmons reagents, ethyl (diarylphosphono)acetates. J. Org. Chem. 62, 1934-1939 
(1997).

880 106. Still, W. C. \& Gennari, C. Direct synthesis of Z-unsaturated esters. A useful modification of the Horner-Emmons olefination. Tetrahedron Lett. 24, 4405-4408 (1983).

107. Paterson, I. \& Lyothier, I. Total synthesis of (+)-discodermolide: An improved endgame exploiting a Still-Gennari-type olefination with a C1-C8 $\alpha$ ketophosphonate fragment. Org. Lett. 6, 4933-4936 (2004).

\section{Table of Contents}

Recent advances in the development of aldol-based synthetic routes to bioactive polyketide natural products are discussed. Representative total syntheses of important anticancer polyketides from the authors' laboratory include spirastrellolide A, rhizopodin, leiodermatolide and chivosazole $\mathrm{F}$ 